\title{
Compliance and Stress Sensitivity of Spur Gear Teeth ${ }^{*}$
}

\author{
R.W. Cornell
}

As the result of recent interest in the possible weight saving obtained by using high contact ratio gear (HCRG) meshes, a computer program was developed using a time history, interactive, closed form solution for the dynamic tooth loads for both low and high contact ratio spur gears (ref. 1). Because the magnitude and variation of the tooth pair compliance with load position can affect the dynamics and loading significantly, and because the tooth root stressing per load varies significantly with load position, it was desirable to include in the dynamic gear program preprocessors and postprocessors, respectively, for calculating these two important factors. Since the tooth forms for HCRG deviate appreciably from the tooth forms for conventional low contact ratio gears (LCRG), improved and simplified methods were developed for calculating the compliance and stress sensitivity for three involute tooth forms as a function of load position-a standard LCRG tooth with no undercut and two HCRG teeth with different forms of undercut (see fig. 1).

The method developed for calculating the compliance of spur gear teeth follows to a great extent that developed by Weber (ref. 2) and includes three factors: (1) the basic deflection of the tooth as a beam, (2) the deflection of the tooth caused by the fillet and foundation flexibility (ref. 3), and (3) the local deflection caused by the contact between the two teeth. The principal improvement in the compliance analysis was for the fillet/foundation deflection, which was found to be defined by different fillet angles for various load positions; whereas previous studies assume a given fillet angle of about $75^{\circ}$. The resulting compliance analysis was evaluated by applying it to available test, finiteelement, and analytic-transformation results and was found to give compliance results which agreed well with measurement and "exact" analyses.

The method developed for calculating the stress sensitivity is an improved and simplified version of the Heywood analysis (ref. 4). Because the tooth forms for HCRG deviate appreciably from conventional LCRG tooth forms, the stress sensitivity analysis had to include most of the factors affecting the stressing. The improved analysis does not assume the peak stress occurs at $30^{\circ}$ from the base of the fillet, as the Heywood analysis does, but allows it to be a function of load position. The sensitivity analysis was found to give results which agreed well with the Heywood (ref. 4) and Kelly and Pederson methods (ref. 13), which, in turn, have been found to correlate well with test results. Evaluation of the modified Heywood stress sensitivity analysis showed that its results compared very well with available test, finite element, and analytic transformation results. The differences between the improved Heywood type stress sensitivity analysis and the conventional Lewis and AGMA analyses were found to be significant for low and high contact ratio gears, being about 25 percent higher for the LCRG and about 15 percent higher for the HCRG.

\section{Gear Tooth Compliance}

\section{Derivation of Compliance Formula.}

The determination of the compliance of gear teeth is considerably more difficult than determining the stress sensitivity because it is an integral function of the entire loaded tooth, rather than just a function of the section properties at the peak stress point and the load location. In addition, because of the stubbiness of the teeth, the foundation and shear effects are important. The method developed herein parallels to a great extent Weber's work (ref. 2) but using O'Donnell's foundation factors (refs. 3 and 5). The total compliance or flexibility of a gear tooth at the point of

\footnotetext{
*Work done under NASA contract NAS3-22138.

†Previously published in J. Mech. Des., vol. 103, no. 2, Apr. 1981. $\ddagger$ Hamilton Standard Division of United Technologies Corp.
} 

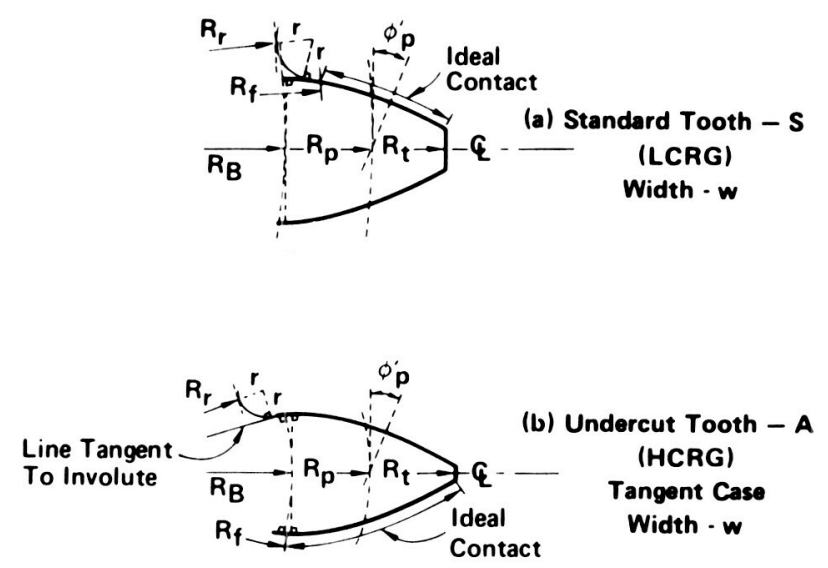

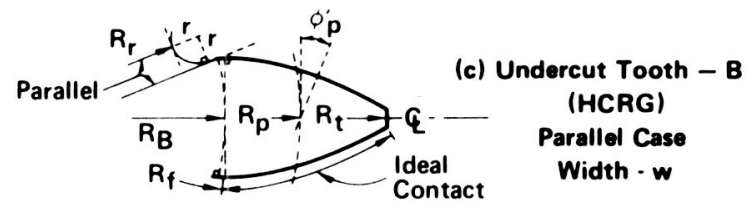

Figure 1. - Gear tooth geometries.

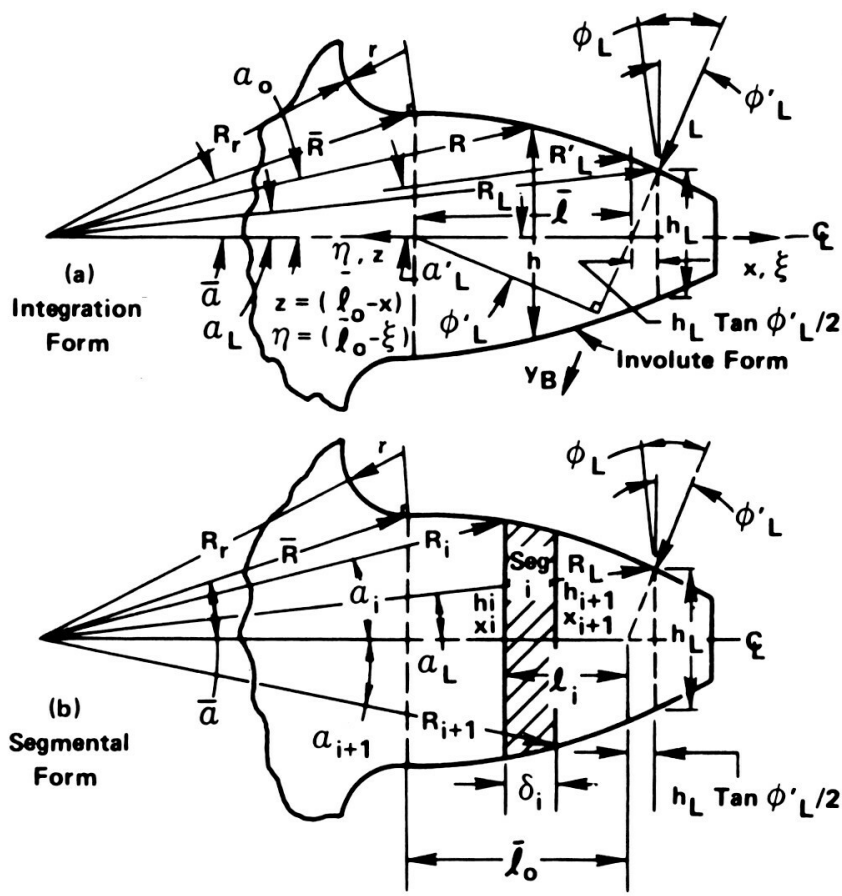

Figure 2. - Beam compliance of gear tooth.

load, $y_{T}$, is made up of three deflections: (1) the basic tooth as a cantilever beam, $y_{B}$; (2) the fillet and foundation, $y_{F}$; and (3) the local contact and compression, $y_{L}$. The compliance, $C$, of a gear tooth pair, 1 and 2, is their combined deflection per unit of load at the contact position or

$$
\begin{aligned}
C=\left(y_{T 1}+y_{T 2}\right) / L & =\left[\left(y_{B 1}+y_{B 2}\right)\right. \\
+ & \left.+\left(y_{F 1}+y_{F 2}\right)+\left(y_{L}\right)\right] / L
\end{aligned}
$$

where $L$ is the applied load and the deflections $y$ are in the direction of the load. The derivation of the three factors in equation (1) follows.

In order to determine the beam compliance of a gear tooth its geometry must be defined over its entire load length. Three different involute tooth forms are considered in this study, which depend on the contact ratio, number of teeth and pitch, and manufacturing process. The three involute tooth forms are depicted in figure 1, form S being for standard LCRG teeth with no necking and forms A and B being for HCRG and small radium LCRG teeth. For tooth form S the tangency of the fillet radius with the involute form occurs outboard of the base circle. For forms A and B the tangency with the tooth form occurs inboard of the base circle. The tooth form inboard of the base circle is machined along a line tangent to the involute surface at the base circle for form $A$, whereas it is plunged ground along a line parallel to the fillet radius centerline for form $\mathrm{B}$. The appendix gives the expressions for defining the tooth geometry for three forms of teeth. The applicable tooth geometry, form $\mathrm{S}, \mathrm{A}$, or B in figure 1, is determined by the expressions

Form S: $\left(R_{r}^{2}+2 r R_{r}\right) \geq R_{B}^{2}$

Form A or B: $\left(R_{r}^{2}+2 r R_{r}\right)<R_{B}^{2}$

Whether form A or B applies is defined by the manufacturing process used, that is, fillet region made tangent or plunge ground, respectively. Having analytically defined the geometry of the gear tooth, the compliance of the tooth can be determined.

The deflection and, therefore, compliance of a gear tooth over its beam portion is easily obtained using elementary strength of materials. Referring to figure 2(a), the total bending and shear 
deflection in the direction of and at the applied tooth load, $L$, which is at radius $R_{L}$ or position $S$ along the line of action, can be expressed in integral form as

$$
\begin{aligned}
y_{B}=\frac{L \operatorname{Cos}^{2} \phi_{L}}{E} \int_{0}^{i_{o}} \\
\quad\left\{\int_{z}^{I_{o} \eta} \frac{\eta}{I} d \eta+\frac{2.40(1+\mu)+\operatorname{Tan}^{2} \phi_{L}^{\prime}}{A}\right\} d z
\end{aligned}
$$

where $I$ is the section modulus of the tooth as a function of $\xi=x$ or $n=z ; n=(\bar{l}-\xi)=z=(\bar{l}-x)$ and is the distance along the centerline of the tooth from the load position; a value of 1.2 has been assumed for the shear factor based on a rectangular tooth; $G=E / 2(1+\mu)$; and $A$ is the cross-sectional area as a function of $x$ or $z$. The deflection of the basic tooth can also be defined in a summation expression rather than integral form (see fig. 2(b)), which would be more applicable for a hand calculation or a programmable calculator. In this case the tooth beam deflection at and in the direction of the load is

$$
\begin{aligned}
y_{B}= & \frac{L \operatorname{Cos}^{2} \phi_{L}}{E} \sum_{i=1}^{n} \delta_{i} \\
& \left\{\frac{\left(l_{i}^{2}-l_{i} \delta_{i}+\frac{1}{3} \delta_{i}^{2}\right)}{\bar{I}_{i}}+\frac{\left(2.4(1+\mu)+\operatorname{Tan}^{2} \phi_{L}^{\prime}\right)}{\bar{A}_{i}}\right\}
\end{aligned}
$$

where $1 / \bar{I}_{i}=\left(1 / I_{i}+1 / I_{i+1}\right) / 2$ and $\left(1 / A_{i}+1 / A_{i+1}\right) / 2$. Using these inverse forms for the values of $\bar{I}_{i}$ and $\overline{A_{i}}$ improves the accuracy for a small number of elements. In equation (4) $I_{i}=\left(\bar{i}-x_{i}\right)$ and $\delta_{i}=\left(x_{i+1}-x_{i}\right)$ (see the appendix). Both approaches for beam flexibility assume a narrow tooth width, $W$. For wide teeth where $W / h_{p}>5$, the flexibility is decreased by the anticlastic effect, so that the values of $I$ in equations (3) and (4) should be divided by $\left(1-\mu^{2}\right)$.

Because of the fillet and the flexibility of the material to which the tooth is attached, additional deflection will occur at the load (refs. 2, 3, and 5). This fillet and foundation deflection in the direction of the load, $y_{F}$, is a function of the fillet geometry and the load position and direction and is determined by the effective fillet length or angle $\gamma_{F}$ for which the maximum deflection or work occurs at the load. In other references this effective fillet angle has been assumed constant at about 70 (ref. 3) or neglected (ref. 2).

Based on figure 3, O'Donnell (refs. 3 and 5) shows that the deflection at and in the direction of the tooth load due to the foundation effects, $y_{F F}$, for plane stress is

$$
\begin{aligned}
y_{F F}= & \frac{L \operatorname{Cos}^{2} \phi_{L}^{\prime}}{W E}\left[\frac{16.67}{\pi}\left(\frac{l_{F}}{h_{F}}\right)^{2}\right. \\
& \left.+2(1-\mu)\left(\frac{l_{F}}{h_{F}}\right)+1.534\left(1+\frac{\operatorname{Tan}^{2} \phi_{L}^{\prime}}{2.4(1+\mu)}\right)\right]
\end{aligned}
$$

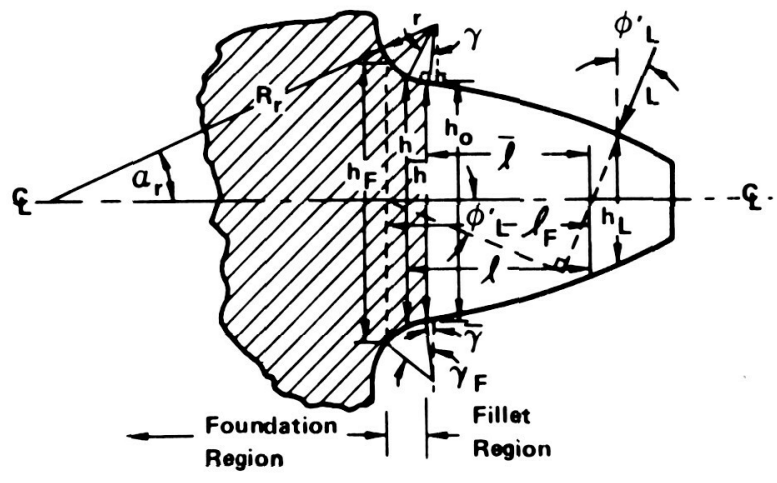

Figure 3. - Fillet and foundation compliance of a gear tooth. 
For wide teeth the expression for plane strain is used or

$$
\begin{aligned}
y_{F F} & =\frac{L \operatorname{Cos}^{2} \phi_{L}^{\prime}}{W E}\left(1-\mu^{2}\right)\left[\frac{16.67}{\pi}\left(\frac{l_{F}}{h_{F}}\right)^{2}\right. \\
& \left.+2\left(\frac{1-\mu-2 \mu^{2}}{1-\mu^{2}}\right)\left(\frac{l_{F}}{h_{F}}\right)+1.534\left(1+\frac{\operatorname{Tan}^{2} \phi_{L}^{\prime}}{2.4(1+\mu)}\right)\right]
\end{aligned}
$$

The O'Donnell coefficients in equations (5) and (6) differ slightly from those given by Weber (ref. 2). The first term in the brackets is the deflection at $L$ due to the rotation caused by the moment at $h_{F}$. The second term is the sum of the deflections at $L$ due to the displacement at $h_{F}$ caused by the moment at $h_{F}$ and the rotation at $h_{F}$ caused by the shear force at $h_{F}$. The first part of the third term is the displacement at $L$ due to the shear force at $h_{F}$, based on the assumption that the effective depth for determining this deflection is $21 / 2$ times the tooth thickness (ref. 2). The second part of the third term is the deflection at $L$ due to the normal component of the load assuming the same relationship holds as indicated by the beam deflection equation (see eqs. (3) and (4)). The question now follows: What values of $l_{F}$ and $h_{F}$ should be used in equations (5) and (6), that is, what is the effective fillet length or angle $\gamma_{F}$ ?

Referring to figure 3, the deflection at and in the direction of the load due to the flexibility of the fillet and foundation, $y_{F}$, the shaded region, is obtained from the summation of the fillet beam deflection, $y_{F B}$, using equations (3) and (4), and the foundation deflection $y_{F F}$, using equation (5) or (6), that is,

$$
y_{F}=y_{F F}+y_{F B}
$$

where $l_{F}=\bar{l}+r\left(\operatorname{Sin} \gamma_{F}-\operatorname{Sin} \bar{\gamma}\right), \quad h_{F}=\bar{h}+2 r\left(\operatorname{Cos} \bar{\gamma}-\operatorname{Cos} \gamma_{F}\right), \quad l_{i}=\bar{l}+r\left(\operatorname{Sin} \gamma_{i}-\operatorname{Sin} \bar{\gamma}\right), \quad$ and $h_{i}=\bar{h}$ $+2 r\left(\operatorname{Cos} \gamma-\operatorname{Cos} \gamma_{i}\right)$. The value of $\gamma_{F}$ is the one that maximizes the value of $y_{F}$ or $y_{T}$, which can be easily done as one integrates or sums up the deflection of the tooth starting at the beginning of the fillet or at the load position.

The significance of maximizing the deflection due to fillet effects can best be realized by expressing in nondimensional form the deflection at the load due to the fillet and foundation flexibility. If this is done, it is found that the effective fillet angle, $\gamma_{F}$, is a function of four quantities $-\bar{l} / \bar{h}, r / \bar{h}, \bar{\gamma}$, and $\phi_{L}^{\prime}$. Figure 4 shows the effect of $r / \bar{h}$ and $\bar{l} / \bar{h}$ on $\gamma_{F}$ for typical values of $\phi_{L}^{\prime}=20^{\circ}$ and $\bar{\gamma}=0$. Apparent from these curves is that assuming a value of $75^{\circ}$ for $\gamma_{F}$ (ref. 3) applies only for small values of $\bar{l} / \bar{h}$ and $r / \bar{h}$ and that a more universal value would be $55^{\circ}$ to $60^{\circ}$. The effects of $\bar{\gamma}$ and $\phi_{L}^{\prime}$ on $\gamma_{F}$ were studied and found to be small. Figure 5 presents the corresponding fillet and foundation flexibility results. Apparent from these curves is that assuming a value of $75^{\circ}$ for $\gamma_{F}$ results in progressively greater error as $\bar{l} / \bar{h}$ and $r / \bar{h}$ increase (HCRG). However, for typical values of $\bar{l} / \bar{h}$ and $r / \bar{h}$, particularly for LCRG, the likely difference will be less than 10 percent from that given by solving for $\gamma_{F}$.

The local compliance, $y_{L}$, consists of the Hertz or line contact deflection plus the compression of each tooth between the point of contact and the tooth centerline. Figure 6 gives the nomenclature for the parameters that determine the local deformation. Three viable approaches were reviewed with regard to calculating the local compliance: (1) an approximate Hertzian and compression approach originally used at Hamilton Standard, (2) a semi-empirical approach developed by Palmgren (ref. 6), and (3) a closed form approach developed by Weber (ref. 2).

The approximate approach assumes that the true Hertz contact deformation, $y_{H}$, must be doubled to account for the cupping action discussed in reference 7, that is,

$$
y_{H} \approx 2 \cdot \frac{b^{2}}{2}\left(\frac{1}{r_{1}}+\frac{1}{r_{2}}\right) \approx \frac{4 I}{\pi W}\left(\frac{1-\mu_{1}^{2}}{E_{1}}+\frac{1-\mu_{2}^{2}}{E_{2}}\right)
$$

The local compression of each tooth between the contact point and tooth centerline is approximated by assuming the load spreads at a $45^{\circ}$ angle, that is from $2 b$ on the top to $2(b+\bar{h})$ at the bottom over a length $\bar{h}$. Assuming the compression deflection is given by the average width, we find

$$
y_{c}=\frac{L}{W}\left[\left(\frac{1-\mu_{1}^{2}}{E_{1}}\right)\left(\frac{\bar{h}_{1}}{2 b+\bar{h}_{1}}\right)+\left(\frac{1-\mu_{2}}{E_{2}}\right)\left(\frac{\bar{h}_{2}}{2 b+\bar{h}_{2}}\right)\right]
$$




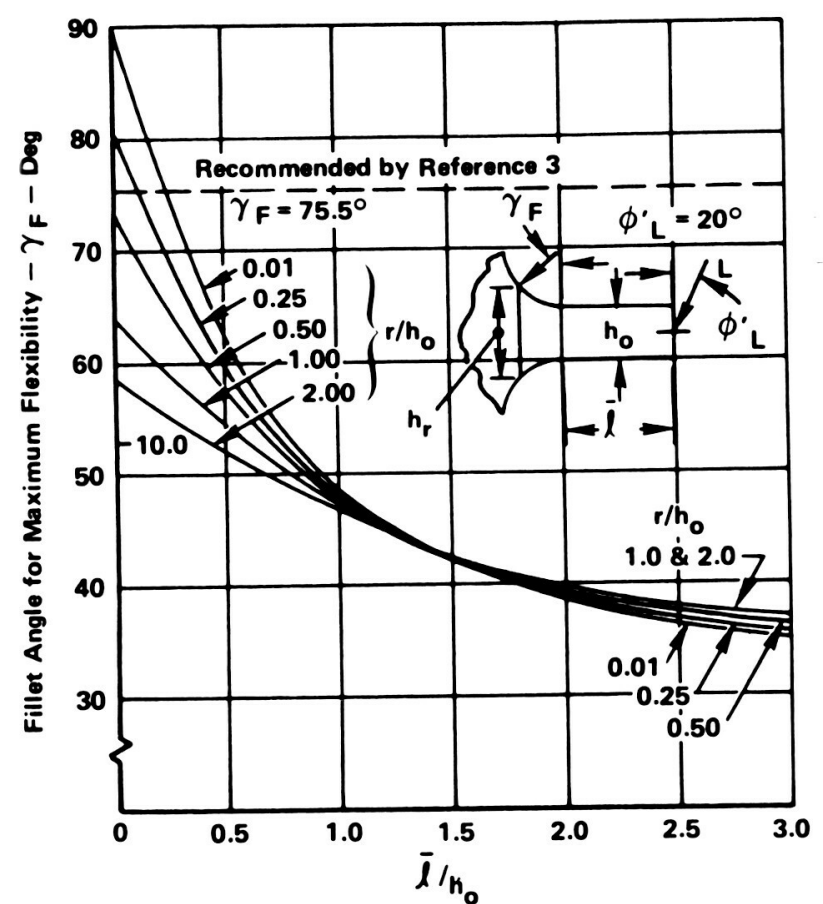

Figure 4. - Fillet angle for maximum flexibility versus load point from fillet.

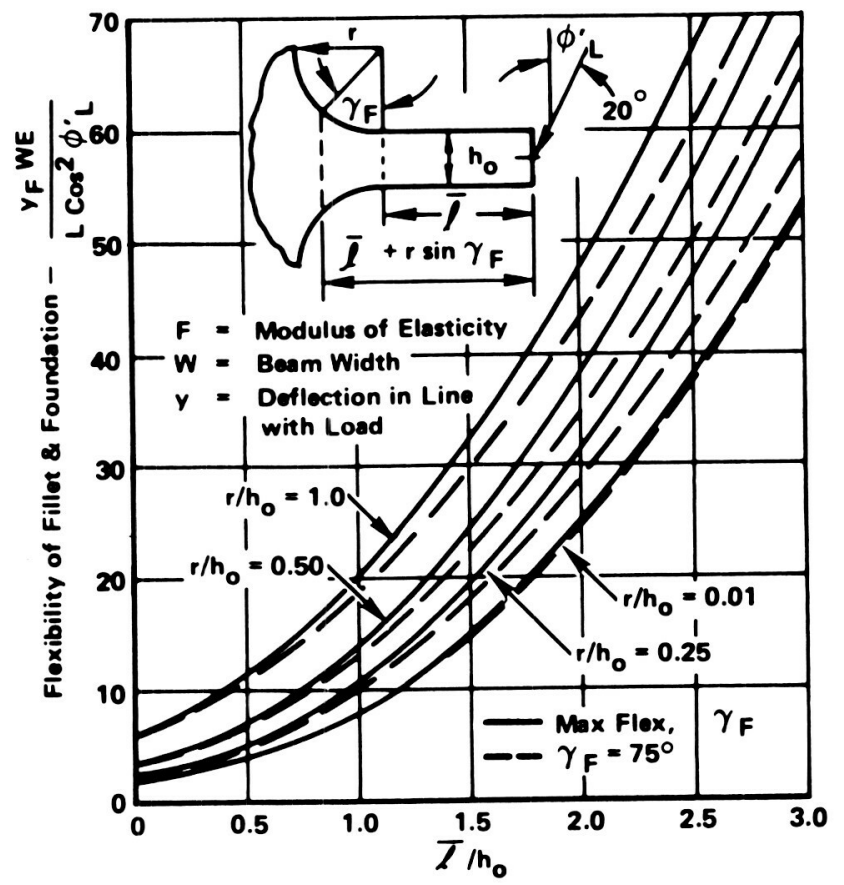

Figure 5. - Flexibility of fillet and foundation versus load position from fillet.

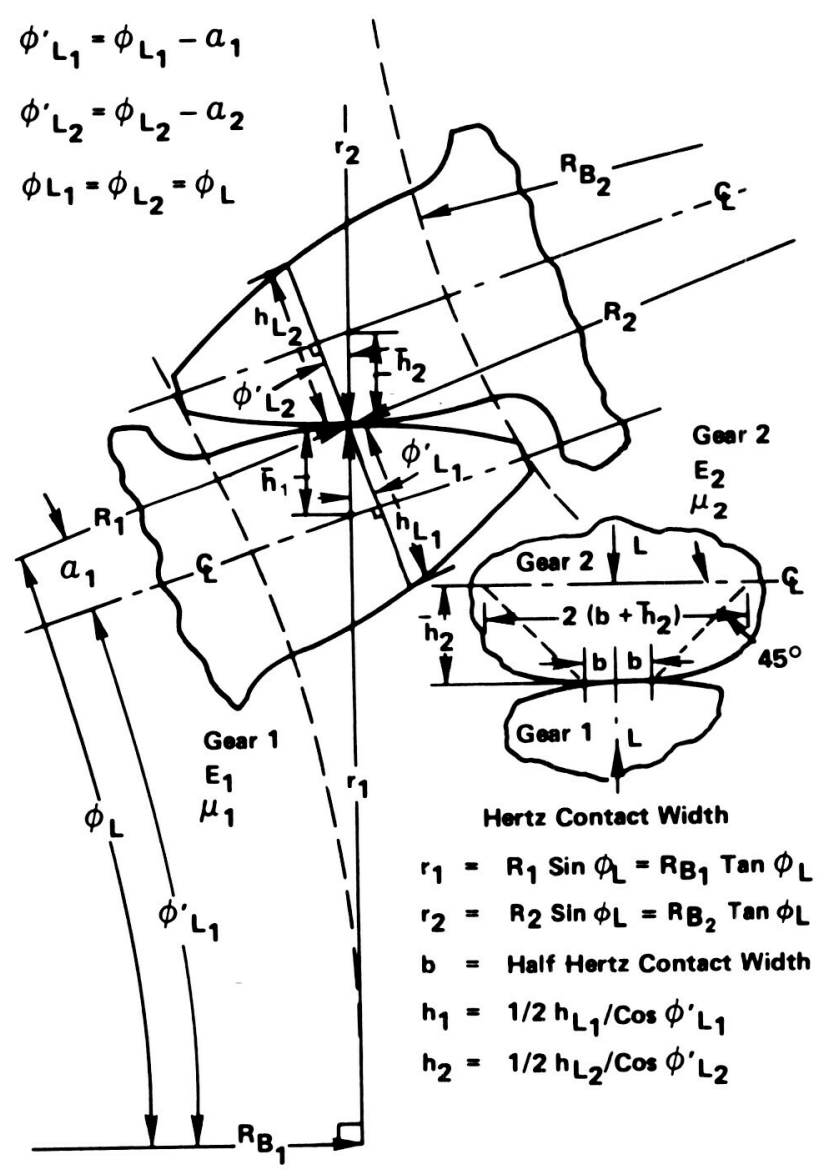

Figure 6. - Nomenclature for local compliance. 
where

$$
b=\left\{\frac{4 L}{\pi W}\left[\left(\frac{1-\mu_{1}^{2}}{E_{1}}\right)+\left(\frac{1-\mu_{2}^{2}}{E_{2}}\right)\right] /\left[1 / r_{1}+1 / r_{2}\right]\right\}^{1 / 2}
$$

Assuming $\bar{h}_{1} / b$ and $\bar{h}_{2} / b$ are both greater than 1 , the local compression of the two teeth reduces to

$y_{c} \approx \frac{L}{W}\left[\left(\frac{1-\mu_{1}^{2}}{E_{1}}\right)+\left(\frac{1-\mu_{2}^{2}}{E_{2}}\right)\right]$

so that the overall local compression of the two teeth is

$y_{L}=y_{H}+y_{c}=\frac{4 L}{\pi W}\left[\left(\frac{1-\mu_{1}^{2}}{E_{1}}\right)+\left(\frac{1-\mu_{2}^{2}}{E_{2}}\right)\right]\left[1+\frac{\pi}{4}\right]$

which for $E_{1}=E_{2}$ and $\mu_{1}=\mu_{2}$ reduces to the simple expression

$y_{L} \approx 3.57 \frac{4\left(1-\mu^{2}\right)}{\pi E} \frac{L}{W} \approx 4.55\left(1-\mu^{2}\right) \frac{L}{W E}$

Although equations (12) and (13) show $y_{L}$ increases linearly with $L / W$, in actuality it increases at a slightly lower rate because the effect of the contact width was neglected. This nonlinear effect can be included if desired.

Reference 6 presents an expression for the local deformation based on the semi-empircal equation developed by Palmgren for contacting cylinders in roller bearings. Because only half a tooth thickness is being compressed instead of the entire roller, the local tooth deflection was assumed to be half that for the roller bearing or

$y_{L}=\frac{1.275 L^{.9}}{E_{i 2}^{9} W^{\cdot 8}}=\frac{4\left(1-\mu^{2}\right) L}{\pi E_{12} W}\left\{1.10 \frac{W^{2} E_{12}}{L}\right\}^{.1}$

where $1 / E_{12}=\left(1 / E_{1}+1 / E_{2}\right) / 2$. Weber in reference 2 developed an expression specifically for the local deformation of two gear teeth. In order to obtain a closed form solution, he assumed small deformations so that just the first two terms of the binomial expansion of the deformation needed to be used, that is,

$$
\begin{aligned}
& y_{L}=\frac{2 L}{\pi W} {\left[\left(\frac{1-\mu_{1}^{2}}{E_{1}}\right)\left\{\ln \frac{2 \overline{h_{1}}}{b}-\left(\frac{\mu_{1}}{2\left(1-\mu_{1}\right.}\right)\right\}\right.} \\
&\left.+\left(\frac{1-\mu_{2}^{2}}{E_{2}}\right)\left\{\ln \frac{2 \bar{h}_{2}}{b}-\left(\frac{\mu_{2}}{2\left(1-\mu_{2}\right.}\right)\right\}\right]
\end{aligned}
$$

where $b$ is given by equation (10). If $E_{1}=E_{2}$ and $\mu_{i}=\mu_{2}$, equation (15) reduces to

$$
y_{L}=\frac{4\left(1-\mu^{2}\right)}{\pi E} \frac{L}{W}\left[\ln \left(2 \frac{\sqrt{\overline{h_{1}} \overline{h_{2}}}}{b}\right)-\left(\frac{\mu}{2(1-\mu)}\right)\right]
$$

All of the expressions for the local deformation are nonlinear with load because of the Hertz half contact width $b$. For simplicity the nonlinearity can be circumvented by assuming a value of $b$ based on the maximum nominal value of tooth load during the mesh, that is, $T / C R_{\min } \cdot \operatorname{Cos} \phi_{p} R_{p}$, or assuming a maximum value of Hertz stress. This latter option should be used after the initial dynamic gear tooth analysis is run and a first approximation of the maximum Hertz stress is obtained including dynamic effects.

In order to decide which of the three local compliance methods should be adopted, they were evaluated for several cases. The first case was for a pair of steel, standard 2 -in. pitch radius, 8 pitch, 0.375 -in. wide, $20^{\circ}$ pressure angle gears in contact at the pitch radius ( $\bar{h}=0.0998$ in.) under load levels of $L / W=1279$ and $2875 \mathrm{lb} /$ in $(q=140000$ and 210000 psi), respectively. The second case is from reference 2 and was for the meshing of an 18 tooth, steel gear with a rack under three loading conditions, where $\bar{h}_{1}=0.80 m, \bar{h}_{2}=0.84 m, r_{1}=3.1 \mathrm{~m}$, and $r_{2}=\infty$. Here, $m$ is the tooth module-pitch diameter in millimeters divided by the number of teeth. The local deflections predicted by the three methods for these two cases are summarized in table 1. For the first case, the empirical method gives 
Table 1 Comparison of Methods for Calculating Local Tooth Compliance: Approximate; Empirical (Palmgren); Closed Form (Weber)

\begin{tabular}{|c|c|c|c|c|c|c|c|}
\hline \multirow{2}{*}{\multicolumn{2}{|c|}{ Fector }} & \multirow[b]{2}{*}{ Equation } & \multicolumn{2}{|c|}{ Gear Ceen 1} & \multicolumn{3}{|c|}{ Geer Cene 2} \\
\hline & & & \multicolumn{2}{|c|}{$\begin{array}{c}16 \mathrm{Tcoth} / 16 \mathrm{Tecth} \\
8 \text { Pitch, } W=0.375 \mathrm{in} ., R_{P}=2.0^{\prime \prime} \\
E=30 \times 10^{6} \text { psi: } \phi_{P}=20^{\circ}: \bar{h}=0.0998 "\end{array}$} & \multicolumn{3}{|c|}{$\begin{array}{c}18 \mathrm{Tecth} / \infty \mathrm{T} \text { coth } \\
\hbar_{1}=0.80 \mathrm{~m}, \hbar_{2}=0.84 \mathrm{~m} ; r_{1}=3.1 \mathrm{~m} ; r_{2}=\infty \\
E=2.15 \times 106 \mathrm{Kg}_{9} / \mathrm{cm}^{2}, \mathrm{~m}=\text { Module in } \mathrm{mm}\end{array}$} \\
\hline Loed/Width & & LM & $1279 \mathrm{lb} / \mathrm{in}$. & $2875 \mathrm{lb} / \mathrm{in}$. & $16.16 \mathrm{Kgm} / \mathrm{cm}^{2}$ & $23.09 \mathrm{Kgm} / \mathrm{cm}^{2}$ & $32.33 \mathrm{Kgm} / \mathrm{cm}^{2}$ \\
\hline Merte Streas & & 9 & $140 \mathrm{ksi}$ & 210 ksi & $1400 \mathrm{Kg} / \mathrm{cm}^{2}$ & $2000 \mathrm{Kg} / \mathrm{cm}^{2}$ & $2800 \mathrm{Kg} / \mathrm{cm}^{2}$ \\
\hline Melf Conteset & Width & b & $0.00581 \mathrm{in}$ & 0.00871 in. & $0.00735 \mathrm{~m}$ & $0.01050 \mathrm{~m}$ & $0.0147 \mathrm{~m}$ \\
\hline $\begin{array}{l}\text { Local } \\
\text { Compliance } \\
\frac{v \pi E W}{L L\left(1 \cdot \mu^{2}\right)}\end{array}$ & $\begin{array}{l}\text { Approx-Lineer } \\
\text { Approx-Non Lineer } \\
\text { Empirical } \\
\text { Closed Form }\end{array}$ & $\begin{array}{r}(13) \\
(9) \\
(14) \\
(16)\end{array}$ & $\begin{array}{l}3.57 \\
3.41 \\
2.50 \\
3.32\end{array}$ & $\begin{array}{l}3.57 \\
3.34 \\
2.31 \\
2.91\end{array}$ & $\begin{array}{l}3.57 \\
3.52 \\
3.86^{\circ} \\
5.19\end{array}$ & $\begin{array}{l}3.57 \\
3.48 \\
3.73^{\circ} \\
4.83\end{array}$ & $\begin{array}{l}3.57 \\
3.44 \\
3.59^{\circ} \\
4.46\end{array}$ \\
\hline
\end{tabular}

iw Acoumed Equal to $5 \mathrm{~m}$

results about 80 percent of those by Weber's method, probably because it includes a width effect, whereas the approximate method gives 10 to 20 percent high values, particularly for the higher Hertz stressing. For the second case there is considerable difference in the local deflections predicted by the three methods for these relatively low Hertz stress cases. Weber's expression gives values about 20 to 25 percent greater than the other two. Because the empirical method is width dependent and appears to give values somewhat low and because the approximate method does not appear to include the nonlinear effects properly, it was decided to use the closed form expression of Weber's equation (15), for the local compliance.

The overall compliance, $C$, of the tooth pair is obtained by adding the local gear tooth compliance defined by equation (15) with the gross tooth compliances for the two gear teeth $\left(y_{B}+y_{F}\right) / L$ given by equations (3) or (4) and (7). (See eq. (1).) In order to obtain the necessary compliance information for the dynamic gear analysis of reference 1, the tooth pair compliance must be determined for at least five different load contact positions, $S$, along the line of action, so that the compliance can be expressed in the required five term power series

$$
\begin{aligned}
C=C_{o}[ & 1+A\left(S / S_{o}\right) \\
& \left.+B\left(S / S_{o}\right)^{2}+C\left(S / S_{o}\right)^{3}+D\left(S / S_{o}\right)^{4}\right]
\end{aligned}
$$

Here, $S_{o}$ is the reference distance along the line of action corresponding to the tip radius of the gear, $C_{o}$ is the tooth pair compliance for a load at the pitch radius, and $A, B, C$, and $D$ are curve fitting coefficients.

\section{Evaluation of Compliance Formula}

The cantilever beam test and finite elements results of reference 8 provided a means for checking the basic fillet and foundation formulation, because of the three deflection measurements along the beam, the simplicity of the beam itself, and the three different fillet sizes and beam thicknesses. (See fig. 7.) A summary of the comparison of the finite element, O'Donnell, and formulas (4) and (7) theoretical results with test is given in table 2. Although the latter formulas are based on O'Donnell's foundation analysis, the effective fillet length is solved for based on maximum energy, resulting in a fillet length equivalent to an angle $\gamma_{F}$ of about $32^{\circ}$ to $34^{\circ}$, depending on the case. Table 2 shows that all three theoretical methods do quite well at predicting the load deflection; however, the O'Donnell approach appears to be inaccurate for small values of $r / h_{o}$ and $l_{o} / h_{o}$ and for load positions close to the support juncture or small $x$. The error for the formulas herein tends to be more uniform for the various tooth geometries as does the finite element results. Correcting the test results for the Poisson swelling (see ref. 8) makes the error variation with position $x$ nearly uniform at about $+1 \pm 3$ percent for the results based on formulas (4) and (7). However, because of the large load moment arm, the concept of variable effective fillet length developed herein could not be fully confirmed. 


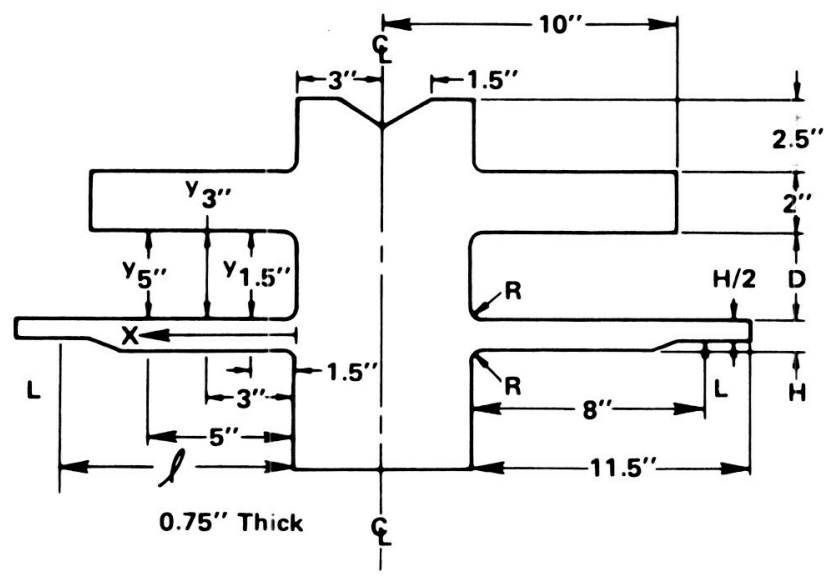

\begin{tabular}{|c|c|c|c|c|c|c|}
\hline \multirow{3}{*}{$\ell / H$} & \multicolumn{3}{|c|}{ Fillet Radius - R - In. } & \multicolumn{3}{c|}{ Beam Thickness $-H-$ In. } \\
\cline { 2 - 7 } & $\begin{array}{c}R / H= \\
0.12\end{array}$ & $\begin{array}{c}R / H= \\
0.31\end{array}$ & $\begin{array}{c}R / H= \\
0.5\end{array}$ & $\begin{array}{c}R / H= \\
0.12\end{array}$ & $\begin{array}{c}R / H= \\
0.3\end{array}$ & $\begin{array}{c}R / H= \\
0.5\end{array}$ \\
\hline 5 & 0.188 & 0.500 & 0.812 & 1.60 & 1.60 & 1.60 \\
8 & 0.125 & 0.313 & 0.500 & 1.00 & 1.00 & 1.00 \\
10 & 0.094 & 0.250 & 0.375 & 0.80 & 0.80 & 0.80 \\
\hline
\end{tabular}

Figure 7. - Geometry of cantilever test specimen

(ref. 8).

Table 2 Percent Error in Deflection Compared to Experimental Data; Cantilever Beam: Load at $l=8$ ", Deflections at $X$, Thickness $H$, Radius $R$; reference [8] and Fig. 9

\begin{tabular}{|c|c|c|c|c|c|c|c|c|c|c|c|}
\hline \multicolumn{3}{|c|}{ Configuration } & \multicolumn{3}{|c|}{$X=1.5^{\prime \prime}$} & \multicolumn{3}{|c|}{$x=3.0^{\prime \prime}$} & \multicolumn{3}{|c|}{$X=5.0^{\prime \prime}$} \\
\hline$R / H$ & R/H & $\begin{array}{c}\gamma_{F}-\text { Deg } \\
\text { Equation } 7\end{array}$ & O'Donnell & F.E. & $\begin{array}{c}\text { Equations } \\
4 \& 7\end{array}$ & O'Donnell & F.E. & $\begin{array}{c}\text { Equations } \\
487\end{array}$ & O'Donnell & F.E. & $\begin{array}{l}\text { Equations } \\
4 \& 7\end{array}$ \\
\hline 0.50 & $\begin{array}{r}5 \\
8 \\
10\end{array}$ & $\begin{array}{l}34 \\
34 \\
34\end{array}$ & $\begin{array}{l}+6 \\
+5 \\
+3\end{array}$ & $\begin{array}{l}-8 \\
-3 \\
-3\end{array}$ & $\begin{array}{r}+2 \\
0 \\
-2\end{array}$ & $\begin{array}{r}+7 \\
0 \\
+7\end{array}$ & $\begin{array}{r}-4 \\
-4 \\
+4\end{array}$ & $\begin{array}{r}+1 \\
0 \\
0\end{array}$ & $\begin{array}{l}+1 \\
+4 \\
+4\end{array}$ & $\begin{array}{l}-6 \\
+1 \\
+2\end{array}$ & $\begin{array}{r}+4 \\
0 \\
-4\end{array}$ \\
\hline 0.31 & $\begin{array}{r}5 \\
8 \\
10\end{array}$ & $\begin{array}{l}32 \\
32 \\
32\end{array}$ & $\begin{array}{l}-5 \\
-3 \\
-4\end{array}$ & $\begin{array}{r}-4 \\
+1 \\
0\end{array}$ & $\begin{array}{r}1 \\
-4 \\
-3\end{array}$ & $\begin{array}{l}-3 \\
+2 \\
-2\end{array}$ & $\begin{array}{r}-3 \\
+4 \\
0\end{array}$ & $\begin{array}{l}-1 \\
+4 \\
-4\end{array}$ & $\begin{array}{r}0 \\
-2 \\
+1\end{array}$ & $\begin{array}{r}0 \\
-1 \\
+2\end{array}$ & $\begin{array}{r}3 \\
-2 \\
+1\end{array}$ \\
\hline 0.12 & $\begin{array}{r}5 \\
8 \\
10\end{array}$ & $\begin{array}{l}32 \\
32 \\
32\end{array}$ & $\begin{array}{r}-11 \\
-8 \\
-7\end{array}$ & $\begin{array}{l}-6 \\
-3 \\
-2\end{array}$ & $\begin{array}{r}+3 \\
0 \\
-2\end{array}$ & $\begin{array}{l}-6 \\
-5 \\
-4\end{array}$ & $\begin{array}{l}-3 \\
-2 \\
-2\end{array}$ & $\begin{array}{l}+5 \\
+3 \\
-1\end{array}$ & $\begin{array}{r}0 \\
0 \\
+1\end{array}$ & $\begin{array}{l}+1 \\
+2 \\
+3\end{array}$ & $\begin{array}{r}+3 \\
+1 \\
0\end{array}$ \\
\hline \multicolumn{3}{|c|}{ Average \pm Variation } & $-3 \pm 8$ & $-3 \pm 5$ & $-0.6 \pm 3$ & $-0.5 \pm 6$ & $-1 \pm 5$ & $0.8 \pm 4$ & $+1 \pm 3$ & $0.5 \pm 3$ & $1 \pm 3$ \\
\hline
\end{tabular}

In order to evaluate the compliance method herein for predicting the effects of axial compression, partial fillet, and beam stiffness present in actual spur gear teeth, it was applied to a number of the tooth configurations analyzed by complex, analytic transformation (refs. 9 and 10) and by finite element analysis (ref. 11). Reference 9 analyzed the beam deflection of the tooth centerline at various load locations for standard $20^{\circ}$ pressure angle, full depth gears with 20 to 80 teeth and compared the results to those predicted by Weber (ref. 2). The results, which are for plane strain, are reproduced in figure 8 along with the plane strain results predicted by the beam compliance method herein. The shape of the curves with load position along the line of contact, $S / P$, and the relative effect of number of teeth are similar for all three methods; however, there is quite a difference in their normalized compliance, $y E W / L$. In general, the transformation compliances (ref. 9) are about 50 percent of those by Weber and about 60 percent of those predicted by formulas (4) and (7).

Very important to the accuracy of the transformation method is the reference point used to define the deflection. If this is chosen close to the base of the tooth, low relative deflections will result. Reference 9 does not define the deflection location. The importance of the reference location is illustrated by the finite element results of reference 11 for 17 and 45 tooth gears, which are plotted in figure 8 . A review of the investigatory results in reference 11 shows that by restricting the length of the foundation of the finite element model to that between the fillet centerlines, the tooth deflection at the tip was decreased at least 10 percent. If the results of reference 11 are corrected accordingly, the finite element compliance results for the 45 and 17 tooth gears would be about 85 and 95 percent, 
respectively, of those predicted by the method herein. Also, the shapes of the compliance curves are more consistent with the other results, for the added correlation increases as $S / P$ becomes more negative. Figure 9 gives the derived values of effective fillet angle, $\gamma_{F}$, for the various load positions and gear teeth which will result in the maximum deflection or work done by the applied load. For load positions inboard of the pitch circle, the assumed value of $75^{\circ}$ by O'Donnell is a good approximation; however, for load positions towards the tooth tip, particularly for HCRG, the effective angle should be considerably less resulting in greater flexibility.

As a further check on the accuracy of the beam and fillet compliance formulas (4) and (7), they were used to predict some of the tooth pair beam stiffnesses presented in reference 10, which used the same analytic transformation method as reference 9. Because the results included the local effects based on Weber (ref. 2), they were corrected for this effect. Table 3 summarizes the results and the corresponding results from reference 9 and formulas (4) and (7). Apparent is the very good correlation of the results of this work and reference 10, whereas those of reference 9 (fig. 8) appear low. The differences between the results of references 9 and 10 are strange because they are based on the same transformation equations; however, the reference points for defining the tooth deformation might be different. In general, the results using the compliance beam formulas herein and those of reference 10 agree within 20 percent, and for the tooth pair they agree within 1 percent.

Reference 12 presents the measured stiffness of a pair of standard form, steel gear teeth with the load at the pitch radius. The $20^{\circ}$ pressure angle gears were $3 / 4$-in. wide and had a diametral pitch of 3 , one with 27 teeth and the other with 18 teeth. The measured stiffnesses at 1275 and $1492 \mathrm{lb}$ tooth loads were $1.28 \times 10^{6}$ and $1.49 \times 10^{6} \mathrm{lb} / \mathrm{in}$, respectively. The theoretical method herein gives tooth stiffnesses of 1.37 and $1.38 \times 106 \mathrm{lb} / \mathrm{in}$, respectively. The local flexibility represented about 25 percent of the overall flexibility. These results compare very favorably with the measured values, being only about 1 percent greater than their average value. This, coupled with the good correlation with the tooth pair results of reference 10 (see table 3 ) indicates the compliance method presented herein is probably as accurate as any available.

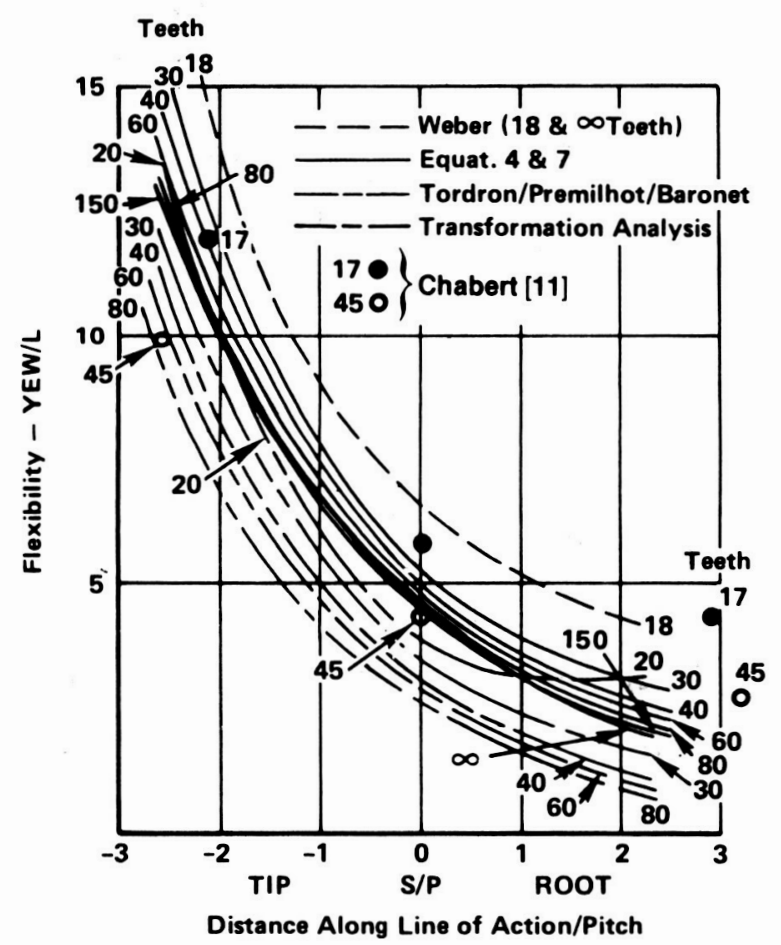

Figure 8. - Normalized beam displacement at load. $\phi_{p}=20^{\circ} ; A=1.0 / P ; D=1.25 / P ; r+0.38 / p ;$ plane strain (refs. 9 and 10).

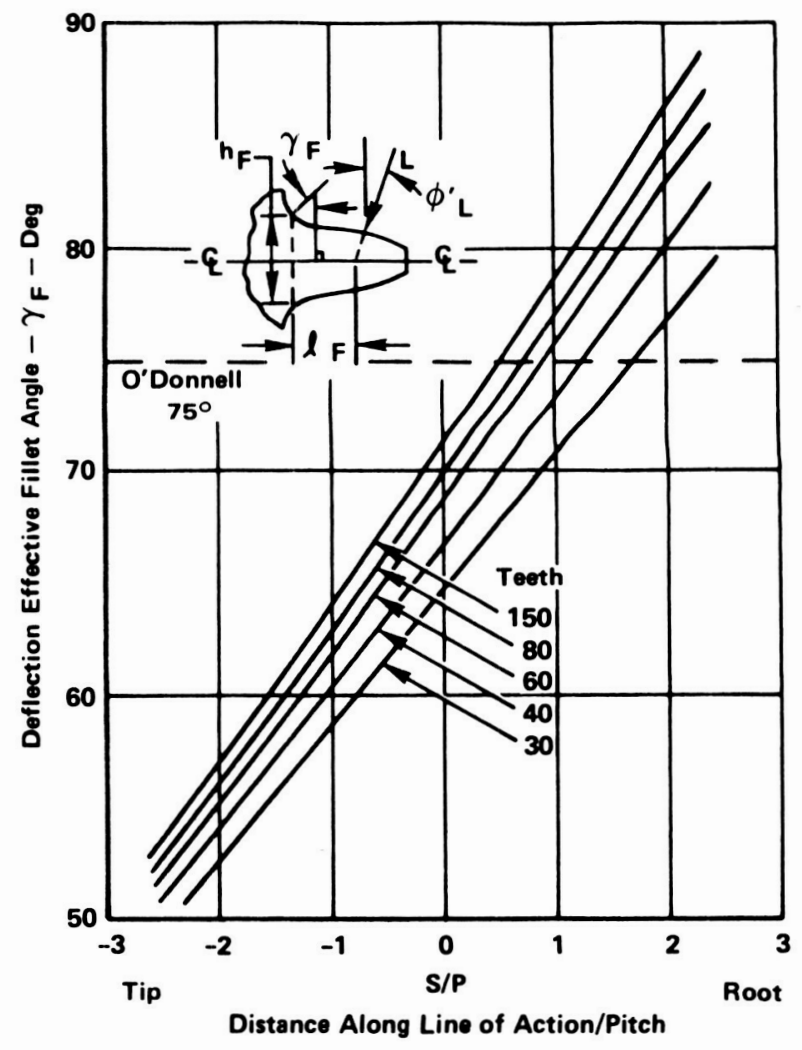

Figure 9. - Deflection effective fillet angle versus load position and gear teeth. 
Table 3 Comparison of Tooth Beam Compliances: Full Depth, $P=4$ Teeth; $\phi=20^{\circ}, A=1.0 / P, D=1.25 / P, r=$ $.38 / P$; references [ 9 and 18 ]

\begin{tabular}{|c|c|c|c|c|c|c|c|c|}
\hline \multicolumn{2}{|c|}{ Case } & \multirow{2}{*}{\multicolumn{4}{|c|}{$\frac{\text { Deflection Under } 1000 \text { Lbs }-10^{-6} \text { In. }}{\text { Chakraborty and Hunoshikatti (9) }}$}} & \multicolumn{3}{|c|}{ Normalized Compliance $-v_{T}$ EW/L } \\
\hline \multirow{2}{*}{$\begin{array}{l}\text { Tooth } \\
\text { Combination } \\
\text { Gear/Pinion }\end{array}$} & \multirow{2}{*}{$\begin{array}{l}\text { Load } \\
\text { Position } \\
\text { S/P }\end{array}$} & & & & & \multirow{2}{*}{$\begin{array}{l}\text { Chakraborty } \\
\& \\
\text { Hunoshikatti }\end{array}$} & \multirow{2}{*}{$\begin{array}{l}\text { Promilhot } \\
\text { Tordion } \\
\text { \& Baronet }\end{array}$} & \multirow{2}{*}{$\begin{array}{c}\text { Equations } \\
487\end{array}$} \\
\hline & & $\left(y_{T 1}+y_{T 2}\right)$ & $y_{\text {Local }}$ & $\left(y_{B_{1}}+y_{F_{1}}+y_{B_{2}}+y_{F_{2}}\right)$ & $\left(y^{\prime} B_{1}+y^{\prime} F_{1}\right)$ & & & \\
\hline $30 / 30$ & 0 & 431 & 139 & 292 & 146 & 4.37 & 3.40 & 5.25 \\
\hline $50 / 50$ & 0 & 380 & 102 & 278 & 139 & 4.16 & 2.90 & 4.85 \\
\hline $70 / 70$ & $\mathbf{0}$ & 405 & 96 & 309 & 154 & 4.61 & 2.70 & 4.50 \\
\hline $30 / 30$ & 2.5 & 741 & 135 & 606 & - & $\begin{array}{r}\text { (Pair) } \\
18.2\end{array}$ & $\begin{array}{c}\text { (Pair) } \\
\sim 33.0\end{array}$ & $\begin{array}{r}\text { (Pair) } \\
18.0\end{array}$ \\
\hline
\end{tabular}

\section{Gear Tooth Stress Sensitivity}

\section{Derivation of Stress Formula.}

For incorporation in the High Contact Ratio Dynamic Gear Program (ref. 1) a gear tooth stress sensitivity or stress per load expression was needed that would be applicable for both LCRG and HCRG. After a review of various methods, it was decided that the Heywood formula (ref. 4) was the most viable; however, it was modified so that it could be more easily applied and yet give approximately the same stress sensitivities as the Kelley/Pederson and Heywood methods. References 13 and 4 had shown that these latter two methods correlate well with experimental and finite element analyses of standard gear teeth.

The modified Heywood formula for tooth stress sensitivity is

$\frac{\sigma W}{L \operatorname{Cos} \phi_{L}^{\prime}}=\left[1+.26\left(\frac{h_{s}}{2 r}\right)^{.7}\right]\left[\frac{6 l_{s}^{\prime}}{h_{s}^{2}}\right.$

(1) (2)

$$
\left.+\sqrt{\frac{.72}{h_{s} l_{s}}}\left(1-\frac{h_{1}}{h_{s}} \nu \operatorname{Tan} \phi_{L}^{\prime}\right)-\frac{\operatorname{Tan} \phi_{L}^{\prime}}{h_{s}}\right]
$$

(3)

(4)

where $\nu \approx 1 / 4$ per Heywood (ref. 4) and the rest of the nomenclature is defined in figure 10. The values of $h_{s}, l_{s}^{\prime}$, and $l_{s}$ are obtained from the gear tooth geometry, the load position, and the point of peak stress in the fillet defined by angle $\gamma_{s}$. This formula is based on simple stress analysis and uses parameters that are easier to define than those used in the Heywood (ref. 4) and Kelley/Pederson (ref. 13) formulas. Equation (18) consists of five factors, in order, (1) stress concentration of the fillet, (2) beam cantilever bending stress, (3) bending load proximity stress, (4) axial load proximity stress, and (5) axial stress. The formula logically makes the proximity effects die out as the bending and axial load get further from the fillet and closer to the neutral axis.

In contrast to the Heywood and Kelley/Pederson methods, for the modified Heywood method the position of the maximum stress in the fillet, which is defined by $\gamma_{s}$ and determines the values of $h_{s}, l_{s}^{\prime}$, and $l_{s}$, is determined by maximizing the stress neglecting the proximity terms in equation (18)-terms (3) and (4). This is done by taking the derivative of equation (18) without the proximity terms, setting it equal to zero, and solving for $\gamma_{s}$. The resulting transcendental equation is

$$
\begin{aligned}
\operatorname{Tan} \gamma_{s i+1}= & \left(1+.16 A_{i}{ }^{7}\right) A_{i} /\left[B_{i}\left(4+.416 A_{i}{ }^{7}\right)\right. \\
& \left.-\left(1 / 3+.016 A_{i}{ }^{\cdot}\right) A_{i} \operatorname{Tan} \phi_{L}^{\prime}\right]
\end{aligned}
$$

where $A_{i}=h_{o} / r+2\left(1-\operatorname{Cos} \gamma_{s i}\right)$ and $B_{i}=l_{o} / r+\operatorname{Sin} \gamma_{s i}$. (See fig. 10.) Equation (19) can be easily solved by iteration in the given form by assuming a value for $\gamma_{s i}$ in the expressions for $A_{i}$ and $B_{i}$ and 


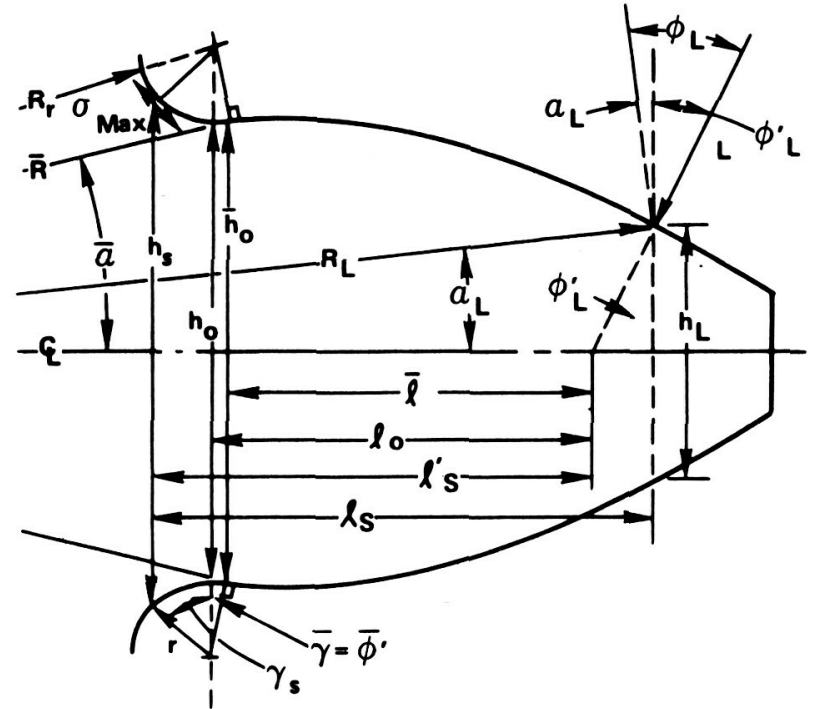

Figure 10. - Nomenclature for modified Heywood formula.

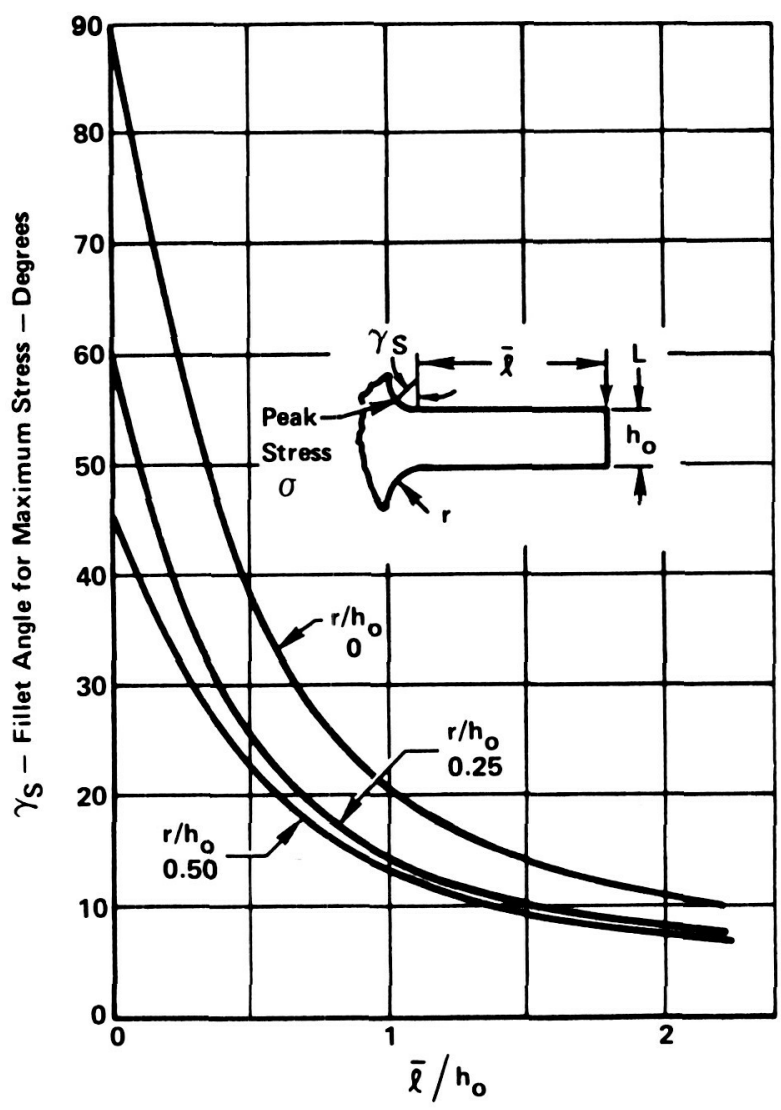

Figure 11. - Fillet angle for maximum stress versus geometry parameters $\bar{l} / h_{0}$ and $r / h_{0}$.

solving for $\gamma_{s i+1}$. Usually only two or three iterations are needed to obtain $\gamma_{s}$ to within $0.1^{\circ}$. Some additional refinement of equation (19) should be done because it gives $\gamma_{s} \approx 0$ for very large values of $l_{o} / r$, whereas it should be about $20^{\circ}$. For short beams, such as gear teeth, this deficiency is probably minor.

Formula (19) was solved for the simple cantilever beam case with no axial load, that is, $\phi_{L}^{\prime}=0$. The position of the maximum stress as defined by angle $\gamma_{s}$ is given in figure 11 as a function of fillet radius, $r / h_{o}$, and load position, $\bar{l} / h_{o}$. The results show that for typical LCRG values of $r / h_{o}$ and $\bar{l} / h_{o}$, the angle of about $30^{\circ}$ or so assumed by Heywood is a fairly reasonable average value. However, for HCRG with greater $\bar{l} / h_{o}$ values, the magnitude of $\gamma_{s}$ for maximum tooth stress should be considerably lower than that used by Heywood. Figure 11 shows that the smaller the fillet the higher up the fillet the peak stress occurs, which is consistent with Jacobson's test results given in reference 14 and Winter's test work in reference 18. In general, the point of peak stress varies significantly with load position and geometry and, therefore, should be included in the derivation of the stress sensitivity of gear teeth.

\section{Evaluation of Stress Formula.}

Various gear tooth designs were evaluated using the modified Heywood formulas (18) and (19) as well as those developed by Heywood (ref. 4) and Kelley/Pederson (ref. 13). Comparison of the results with photoelastic measurements is given in figure 12. This figure shows that all three methods do a good job in predicting the maximum tensile tooth stressing as a function of load position, geometry, and number of teeth. It appears that the modified Heywood method correlates slightly better than the other two in some instances. Because of this and its simplicity in defining the necessary parameters, its use is justified over the other methods. In general, the correlation with the photoelastic results are within about 5 percent, and slightly on the conservative side. 

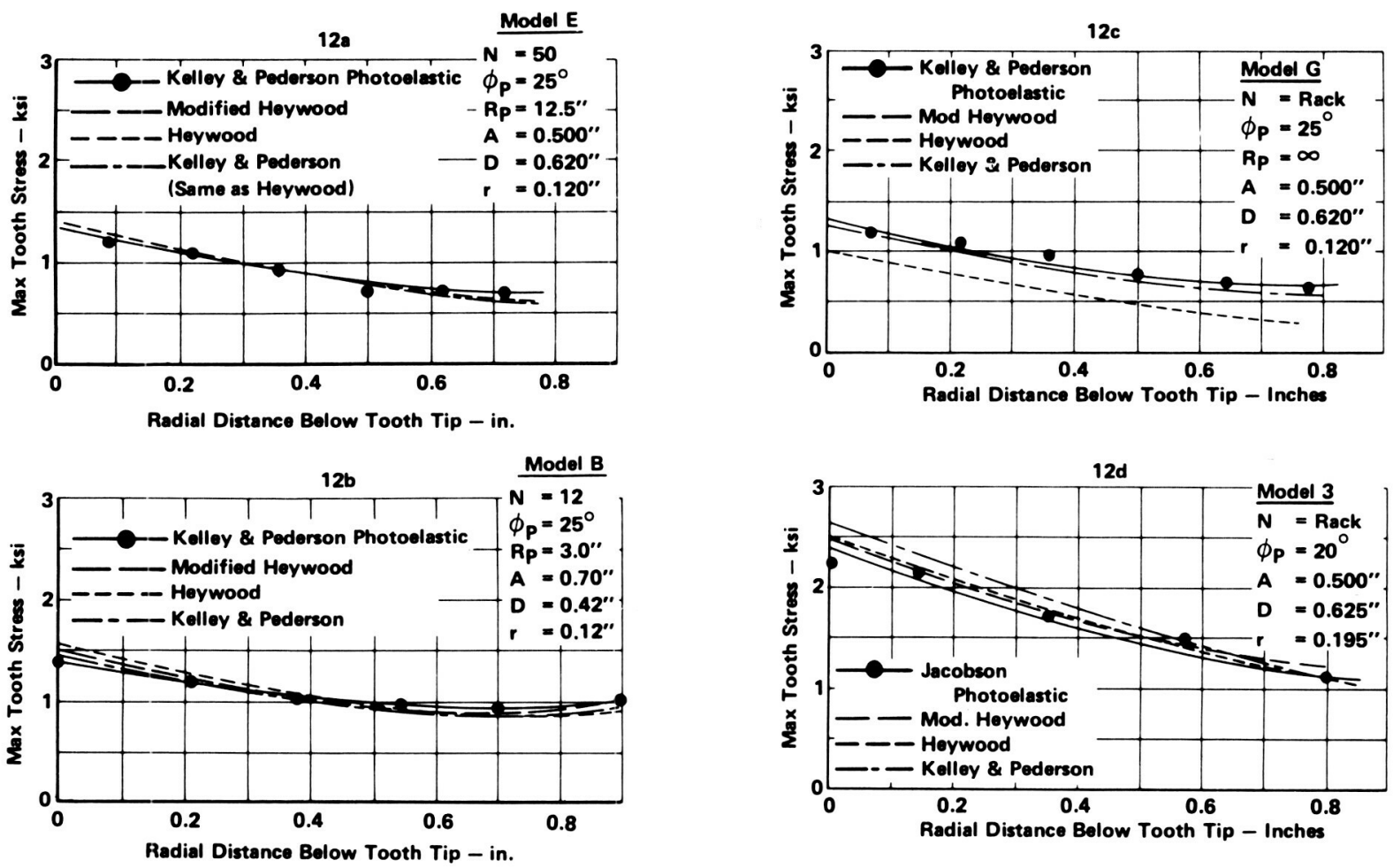

Figure 12. - Improved modified Heywood results versus photoelastic tests, Kelley/Pederson and Heywood.

Table 4 Comparison of Improved Modified Heywood and Exact Methods for Full Depth Involute Spur Gear Teeth: $A=$ $1 / P, D=1.25 / P, r_{20^{\circ}}=.380 / P, r_{25^{\circ}}=.433 / P$; reference $[15]+$

\begin{tabular}{|c|c|c|c|c|c|c|c|c|c|}
\hline \multicolumn{2}{|c|}{ Case } & \multicolumn{4}{|c|}{$\begin{array}{l}\text { Pitch Line Loading } \\
H_{w}=0.0 / P\end{array}$} & \multicolumn{4}{|c|}{$\begin{array}{l}\text { Tip Loading } \\
H_{w}=1.0 / P\end{array}$} \\
\hline \multirow[b]{2}{*}{$\phi_{\mathbf{P}}$} & \multirow{2}{*}{$\begin{array}{l}\text { Number } \\
\text { of } \\
\text { Teeth }\end{array}$} & \multicolumn{2}{|c|}{$\begin{array}{c}\text { Stress Factor } \\
\mathrm{J}_{\mathrm{t}}^{+}\end{array}$} & \multicolumn{2}{|c|}{$\begin{array}{l}\text { Peak Stress } \\
\mathrm{H}_{\mathrm{s}} \times \mathbf{P}\end{array}$} & \multicolumn{2}{|c|}{$\begin{array}{c}\text { Stress Factor } \\
\mathrm{J}_{\mathrm{t}}^{+}\end{array}$} & \multicolumn{2}{|c|}{$\begin{array}{l}\text { Peak Stress } \\
\mathrm{H}_{\mathrm{s}} \times \mathrm{P}\end{array}$} \\
\hline & & "Exact" & $\begin{array}{l}\text { Modified } \\
\text { Heywood }\end{array}$ & "Exact" & $\begin{array}{l}\text { Modified } \\
\text { Heywood }\end{array}$ & "Exact" & $\begin{array}{l}\text { Modified } \\
\text { Heywood }\end{array}$ & "Exact" & $\begin{array}{l}\text { Modified } \\
\text { Heywood }\end{array}$ \\
\hline $20^{\circ}$ & $\begin{array}{r}20 \\
30 \\
40 \\
60 \\
80 \\
150\end{array}$ & $\begin{array}{c}0.328 \\
- \\
0.407 \\
0.462 \\
0.473 \\
0.483\end{array}$ & $\begin{array}{c}- \\
0.378 \\
0.397 \\
0.443 \\
0.459 \\
0.480\end{array}$ & $\begin{array}{c}1.17 \\
- \\
1.16 \\
1.15 \\
1.15 \\
1.14\end{array}$ & $\begin{array}{c}- \\
1.11 \\
1.11 \\
1.12 \\
1.12 \\
1.13\end{array}$ & $\begin{array}{c}0.221 \\
- \\
0.254 \\
0.289 \\
0.291 \\
0.286\end{array}$ & $\begin{array}{c}- \\
0.223 \\
0.238 \\
0.249 \\
0.252 \\
0.260\end{array}$ & $\begin{array}{c}1.14 \\
- \\
1.11 \\
1.11 \\
1.11 \\
1.09\end{array}$ & $\begin{array}{l}- \\
1.01 \\
1.01 \\
1.01 \\
1.01 \\
1.00\end{array}$ \\
\hline $25^{\circ}$ & $\begin{array}{r}20 \\
30 \\
40 \\
60 \\
80 \\
150\end{array}$ & $\begin{array}{c}0.451 \\
- \\
0.494 \\
0.517 \\
0.532 \\
0.569\end{array}$ & $\begin{array}{c}- \\
0.498 \\
0.531 \\
0.565 \\
0.586 \\
0.608\end{array}$ & $\begin{array}{c}1.24 \\
- \\
1.19 \\
1.17 \\
1.17 \\
1.17\end{array}$ & $\begin{array}{c}- \\
1.13 \\
1.13 \\
1.13 \\
1.14 \\
1.14\end{array}$ & $\begin{array}{c}0.307 \\
- \\
0.315 \\
0.317 \\
0.323 \\
0.336\end{array}$ & $\begin{array}{l}0.254 \\
0.280 \\
0.290 \\
0.298 \\
0.304 \\
0.307\end{array}$ & $\begin{array}{c}1.19 \\
- \\
1.15 \\
1.14 \\
1.14 \\
1.14\end{array}$ & $\begin{array}{l}1.00 \\
1.00 \\
0.99 \\
0.99 \\
0.99 \\
0.99\end{array}$ \\
\hline
\end{tabular}

$+\sigma_{t}=L_{t} P / J_{t} W ; \quad W=$ Width: $\quad P=$ Pitch; $L_{t}=$ Tangent Load at Pitch Radius

Table 4 and figure 13 present the comparison of the stress sensitivities for a family of $20^{\circ}$ and $25^{\circ}$ pressure angle, full depth involute gears using the modified Heywood and an "exact" transformation analysis (ref. 15). In general, the trends with number of teeth, load position, and pressure angle are predicted by the modified Heywood formulas. For the $20^{\circ}$ pressure angle gears, the pitch circle loading results correlate very well, but the tip loading results are about 10 percent 
Table 5 Finite Element, Modified Lewis, and Modified Heywood Tooth Stressing: $R_{P}=2.50^{\prime \prime}, \phi_{P}=20^{\circ}, W=$ $1.0^{\prime \prime} ; A=.25 ", D=.289^{\prime \prime}, r=.060^{\prime \prime}, t_{p}=.390^{\prime \prime}$

\begin{tabular}{|c|c|c|c|c|c|c|c|c|c|}
\hline $\begin{array}{c}\text { Parameter } \\
\text { See Figure 10 }\end{array}$ & \multicolumn{3}{|c|}{$\begin{array}{c}\text { Finite Element } \\
\text { \& Impulse Test }\end{array}$} & \multicolumn{3}{c|}{ Modified Lewis } & \multicolumn{3}{c|}{ Modified Heywood } \\
\hline Load Position & 1 & 2 & 3 & 1 & 2 & 3 & 1 & 2 & 3 \\
\hline$R_{L}-$ in. & $\sim 2.70$ & $\sim 2.55$ & $\sim 2.40$ & $\sim 2.70$ & $\sim 2.55$ & $\sim 2.40$ & 2.70 & 2.55 & 2.40 \\
\hline$\phi_{L}^{\prime}-$ deg & 27.10 & 18.83 & 6.62 & 27.10 & 18.83 & 6.62 & 27.15 & 18.88 & 6.68 \\
\hline$h_{S}-$ in. & - & - & - & 0.45 & 0.46 & 0.47 & 0.426 & 0.434 & 0.451 \\
\hline$l_{S}-$ in. & - & - & - & 0.40 & 0.26 & 0.15 & 0.403 & 0.255 & 0.150 \\
\hline$\sigma_{\mathrm{t}} / \mathrm{L}-$ psi/lb & $16^{+}$ & $12.8^{+}$ & 10.6 & 15.3 & 12.2 & 9.3 & 20.2 & 14.7 & 11.7 \\
\hline$\left(\gamma_{S}+\gamma^{\prime}\right)-$ deg & $\sim 10^{*}$ & $\sim 30^{*}$ & $\sim 45^{*}$ & - & - & - & 23.0 & 32.5 & 47.1 \\
\hline
\end{tabular}

"Impulse Failure Test: +Below Surface 0.008"; Therefore Values Low

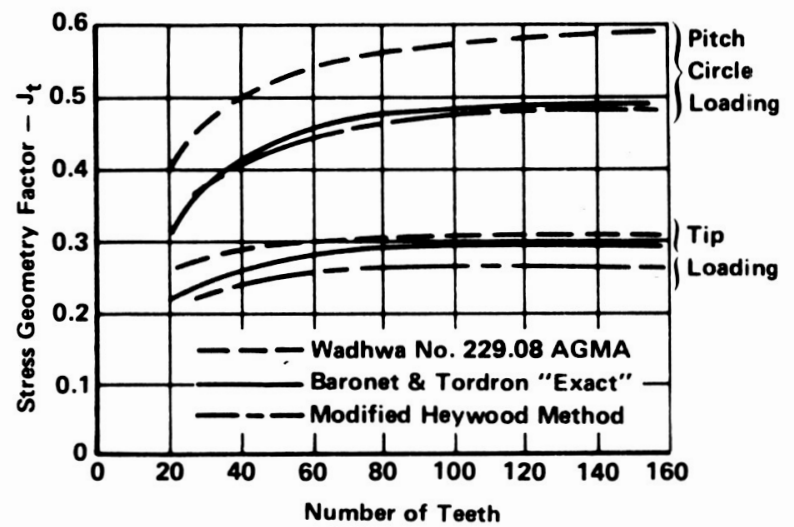

Figure 13. - Comparison of geometry factors from various formulas and "exact" analysis. $\phi_{p}=$ $20^{\circ} ; P=1 ; A=1 / P ; D=1.25 / P ; r=0.38 / P ; \sigma=$ $L_{t} P / J_{t} W$.

high, whereas the reverse is true for the $25^{\circ}$ pressure angle gears. The "exact" analysis indicates the peak stress occurs further up the fillet than the modified Heywood analysis results. (See table 4.) The accuracy of the analytical function in defining the fillet region could influence its results and the correlation with the modified Heywood results.

Wallace and Seireg performed a finite element analysis of a gear tooth (ref. 16) and also conducted impulse strain gage tests of a standard, 4 pitch gear tooth. Comparison of their finite element results, those by the modified Lewis formula, and those by formulas (18) and (19) are summarized in table 5. This summary indicates that the modified Lewis results are a little low, particularly if the finite element results are corrected for the effect of element size. In contrast, the modified Heywood results are slightly higher, 10 to 20 percent, but this difference would be decreased if the effects of the coarse finite element mesh were taken into account. The locations of the peak stressing predicted by the modified Heywood method for the three tested tooth loading positions correlate well with those predicted by the modified Lewis method and the failure locations found during the impulse tests. Some of the discrepancy in the results between the two methods of analysis appears to be due to the definition of the tooth geometry. Although the distance from the load to peak stress, $l_{s}$, is about the same for the two methods, their respective tooth thicknesses, $h_{s}$, are about 5 percent different, which would account for about 10 percent of the differences in the stress sensitivies. 
As a more fundamental check on the modified Heywood stress sensitivity analysis, it was used to calculate the maximum stress and its position for photoelastic models $\mathrm{H}$ and $\mathrm{F}$ tested by Dolan and Broghamer (ref. 17). The first model is a simple rectangular, cantilever beam loaded normally close to the fillet, $\bar{l} / h_{o} \approx 0.55$, whereas the second model is similar to the first but the beam is tapered $15^{\circ}$ on each side with the load normal so as to introduce an axial compressive load. The photoelastic results for the first model gave a tensile stress sensitivity of $\sigma W / L=6.20 / \mathrm{in}$. and a maximum stress position at about $25^{\circ}$ up the fillet. The modified Heywood method gives a stress sensitivity value of 6.06/in., 2 percent low, at an angle of $24^{\circ}$ up the fillet. The photoelastic results for the second model gave a tensile stress sensitivity of $4.46 /$ in. at about $35^{\circ}$ up the fillet, whereas the modifed Heywood method predicts values of $4.37 / \mathrm{in}$. and $33^{\circ}$, respectively. The good correlation in magnitude and position of the maximum tensile stress shows that formulas (18) and (19) can handle accurately loads close to the fillet.

The importance of having an accurate method for calculating the maximum stress in various gear teeth was illustrated in reference 1 . A comparison was made of the calculated tooth stress sensitivity versus load position for both HCRG and LCRG using various conventional and Heywood type analyses. The results, reproduced in figure 14, show that the three Heywood type analyses agree quite well with each other, whereas the usual Lewis and AGMA analyses give lower and significantly different results. The relative differences between the modified Heywood and the Lewis and AGMA results at the load position for maximum likely peak stress are quite different for LCRG and HCRG, being about 20 to 28 percent higher for the LCRG and only about 10 to 18 percent higher for the HCRG, respectively. Such differences would have significant effect on the tooth bending fatigue life.

\section{Improvements in Dynamic Gear Program}

The High Contact Ratio Dynamic Gear Program developed and discussed in reference 1 already incorporated the stress sensitivity formula developed herein. However, the program since has been improved by including a preprocessor which defines the gear tooth structural and manufacturing parameters from a few simple input parameters and calculates the gear tooth pair compliance based on the equations developed herein. A postprocessor has been added which calculates the design outputs of PV, Hertz stress, flash temperature, load, and stressing for the two gears. In addition, the formulation of the basic program was expanded to include centerline error, which affects the pressure angle and length of engagement, and a three term definition of tooth profile relief, $\Delta$, rather than a two term expression (see ref. 1), for example, for engagement

$\Delta_{e}=C_{e}\left(S_{o e}-S_{e}\right)^{2}\left[1+\bar{\gamma}_{e}\left(S_{o e}-S_{e}\right)\right]$

in place of

$\Delta_{c}=C_{e}\left(S_{o e}-S_{e}\right)^{2}$
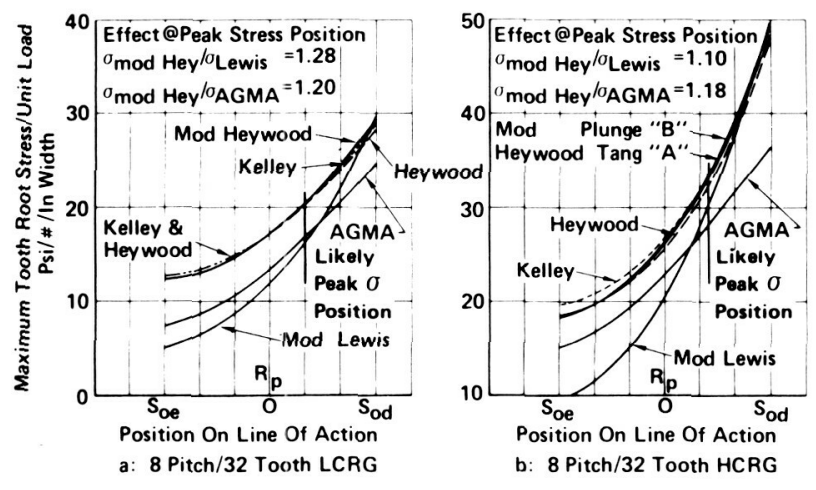

Figure 14. - Comparison of gear tooth stress sensitivities for different analys is methods.

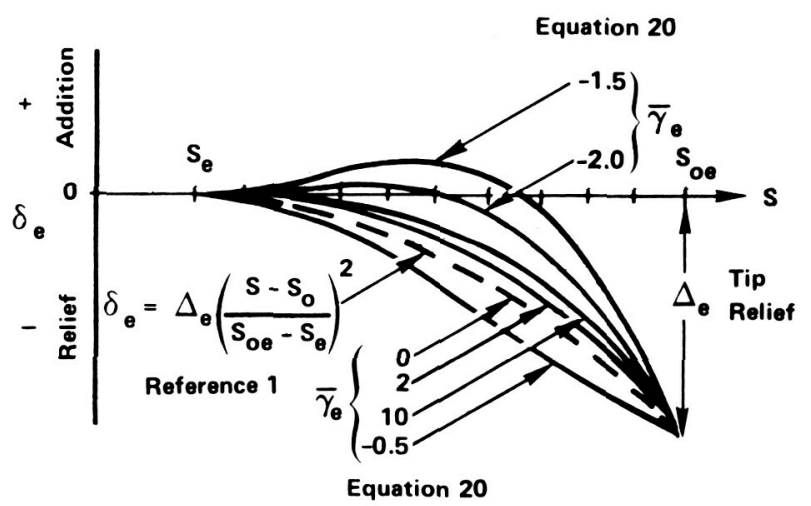

Figure 15. - Tooth profile modification shapes; engagement cam. 


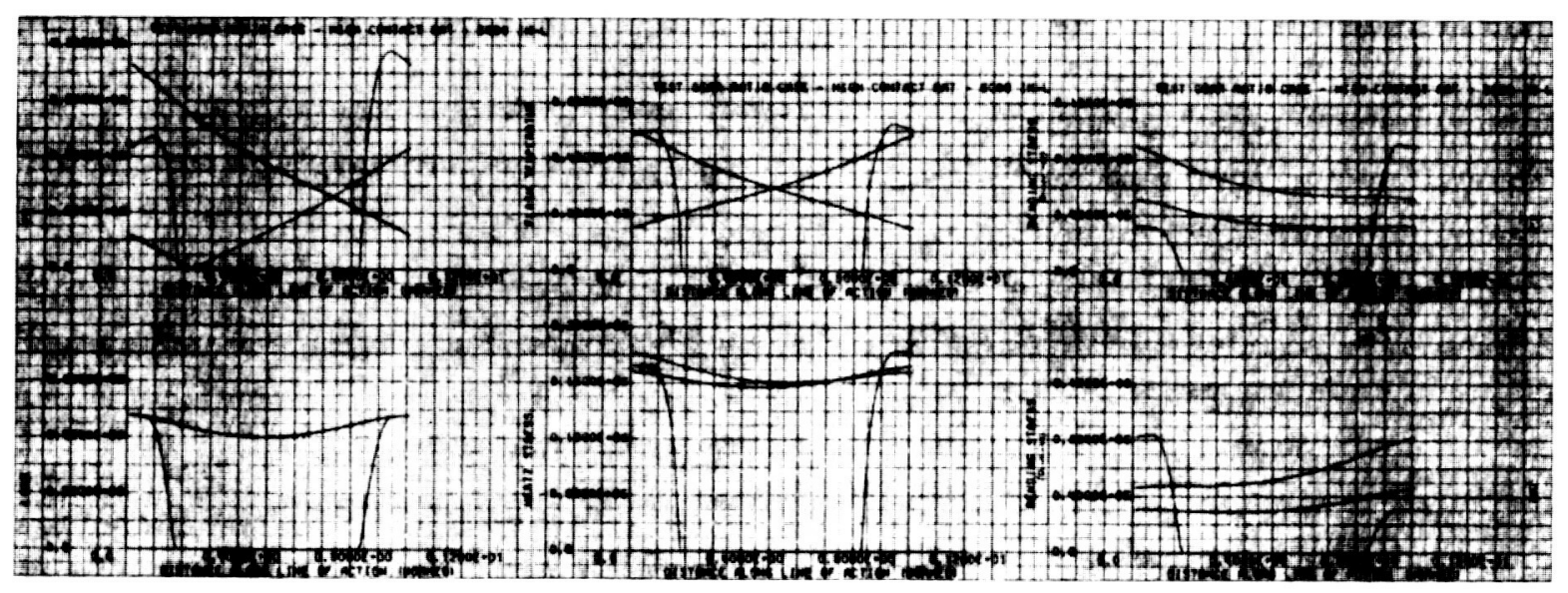

Figure 16. - Dynamic tooth loads and stressing for HCRG-no tooth error case: 2.2 contact ratio, 8 pitch, $20^{\circ}$ pressure angle; 5000 in-lb torque; $44 / 52$ gear ratio; 6-in. center distance; ref. 1 analys is.

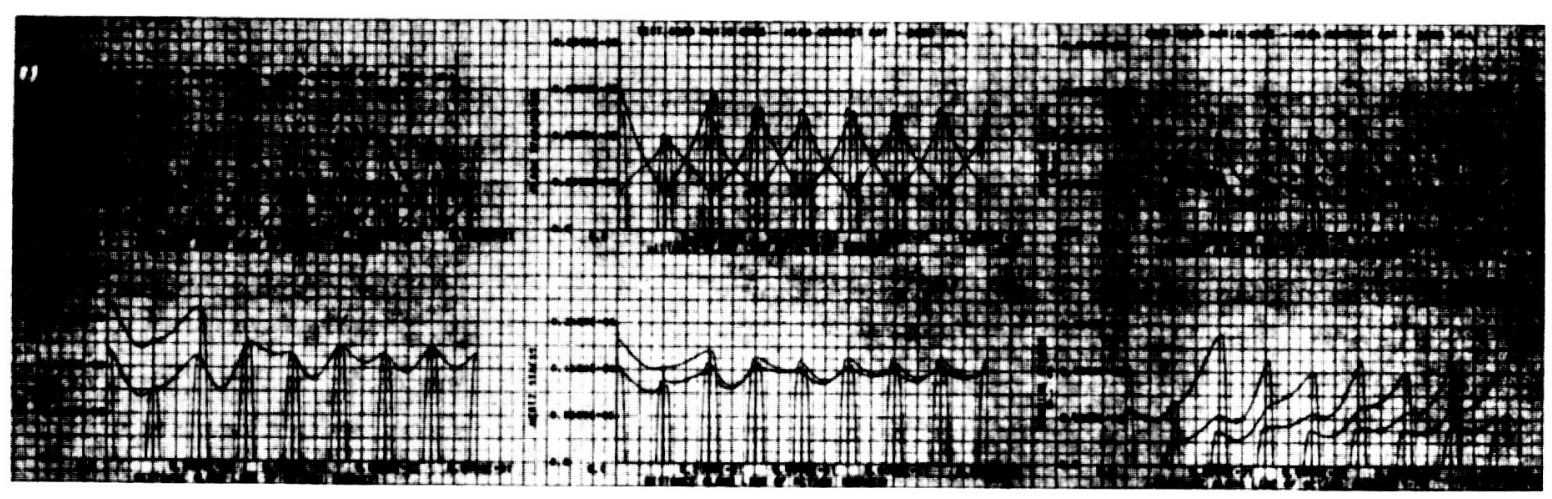

Figure 17. - Dymamic tooth loads and stressing for HCRG-tooth error case: 2.2 contact ratio, 8 pitch, $20^{\circ}$ pressure angle; 5000 in-lb torque; $44 / 52$ gear ratio; 6-in. center distance; ref. 1 analysis.

The effect of this additional parameter $\bar{\gamma}_{e}$ on the allowable profile or cam shapes is shown in figure 15. Figures 16 and 17 are examples of the plotted outputs for the improved program. The first figure depicts the results for an HCRG, 8 pitch, 44/52 tooth pair with a nominal 2.20 contact ratio, a $20^{\circ}$ pressure angle, and no tooth error under $5000 \mathrm{in} . \cdot \mathrm{lb}$. of torque. The second figure is for the same gear pair but with tooth spacing error and is for eight mesh cycles.

\section{Conclusions}

Formulas have been developed based on work done by Heywood (ref. 4), Weber (ref. 2) and O'Donnell (ref. 3) for the stress sensitivity and compliance of low and high contact ratio, involute, spur gear teeth. The parameters used in these formulas require the derivation of the effective fillet length or angle rather than assuming particular values as done by Heywood (ref. 4) and O'Donnell (ref. 3). The stress sensitivity formula is a modified version of the Heywood formula, using simple beam parameters. The compliance formula uses O'Donnell's foundation flexibility factors and Weber's local contact compliance.

The modified Heywood gear tooth stress sensitivity formula was evaluated by comparing its predicted results with test, finite element, and analytic transformation results for gears with various 
pressure angles, tooth proportions, number of teeth, and load contact position. In general, the formula predicts the maximum tensile fillet stress within about 5 percent and gives the proper trends with contact position, number of teeth, and tooth geometry. It also predicts fairly well the location of the peak stress in the fillet. Comparison with similar formulas by Kelley/Pederson and Heywood show good correlation, but with the proposed modified Heywood method giving slightly more consistent results as well as being easier to use.

The beam and foundation portion of the gear tooth compliance formula was evaluated using available test, finite element, and analytic transformation results and found to correlate quite well. The inclusion of a derived, variable effective fillet length or angle appears to improve upon the results which assumed a given effective fillet length. In general, the combined beam and foundation deflection as a function of gear teeth and load contact position agreed well with other methods. The Weber method of calculating the local contact deflection is universally used and was found to give more consistent results than two other methods. The gear tooth pair compliance formula was found to predict the overall compliance (beam + foundation + local) consistent with the test results of Howland.

In summary, although further evaluation of the gear tooth stress sensitivity and compliance formulas presented herein might be desirable, the evaluation results indicate that the formulas predict the spur gear tooth pair stress sensitivity and compliances quite well. 


\section{References}

1. Cornell, R. W.; and Westervelt, W. W.: Dynamic Tooth Loads and Stressing for High Contact Ratio Spur Gears. J. Mech. Des., vol. 100, Jan. 1978.

2. Weber, C.: The Deformations of Loaded Gears and The Effect on Their Load-Carrying Capacity. Sponsored Research (Germany), British Dept. of Scientific and Industrial Research, Report No. 3, 1949.

3. O'Donnell, W. J.: Stress and Deflection of Built-in Beams. ASME Paper No. 62-WA-16, 1974.

4. Heywood, R. B.: Designing by Photoelasticity, Chapman and Hall, Ltd., 1952.

5. Metusz, J. M.; O'Donnell, W. J.; and Erdloc, R. J.: Local Flexibility Coefficients for the Built-in Ends of Beams and Plates. J. Eng. Ind., Aug. 1969.

6. Laskin, I.; Orcut, F. K.; and Shipley, F. F.: Analyses of Noise Generated by UH-1 Helicopter Transmission. USAAVLABS Tech. Report 68-41, June 1968.

7. Cooper, D. H.: Hertzian Contact Stress Deformation Coefficients. ASME J. Appl. Mech., June 1969.

8. Durocher, L. I.; Kosh, W. S.; and Wongphadung, S.: Design Considerations in Force-Deflection Retentions of Cantilever Beams. ASME Paper No. 77-DE-50, May 1977; and supporting information from L. I Durocher, June 29, 1977.

9. Premilhot, A.; Tordion, G. V.; and Baronet, C. N.: An Improved Determination of the Elastic Compliance of a Spur Gear Tooth Acted on by a Concentrated Load. ASME Paper 72-PTG-9, Oct. 1972.

10. Chakraborty, J.; and Hanoshikatti, H. G.: Determination of the Combined Mesh Stiffness of a Spur Gear Pair Under Load. ASME Paper 74-DET-39, 1974.

11. Chabert, G.; Dang Tran, T.; and Mathis, R.: An Evaluation of Stresses and Deflection of Spur Gear Teeth Under Strain. ASME, J. Eng. Ind., Feb. 1974.

12. Howland, J. S.: An Investigation of the Dynamic Loads in Spur Gear Teeth. Masters Thesis-MIT Report, Feb. 1962.

13. Kelley, B. W.; and Pederson: The Beam Strength of Modern Gear Tooth Design. SAE Trans., vol. 66, 1958.

14. Jacobson, M. A.: Bending Stresses in Spur Gear Teeth: Proposed New Design Factors Based on a Photo-Elastic Investigation. Proc. Inst. Mech. Eng., vol. 169, no. 31, 1955, pp. 587-609.

15. Baronet, C. N.; and Tordion, G. V.: Exact Stress Distribution in Standard Gear Teeth and Geometry Factors. ASME, J. Eng. Ind., Nov. 1973.

16. Wallace, D. B.; and Seireg, A.: Computer Simulation of Dynamic Stress, Deformation, and Fracture of Gear Teeth. J. Eng. Ind., Feb. 1974.

17. Dolan, T. J.; and Broghamer, E. L.: A Photoelastic Study of Stresses in Gear Tooth Fillets. University of Illinois Engineering Experimental Station Bulletin No. 335, 1942.

18. Winter, H.; and Hirt, M.: The Measurement of Actual Strains at Gear Teeth, Influence of Fillet Radius on Stresses and Tooth Strength. J. Eng. Ind., Feb. 1974. 


\section{Appendix-Definition of Different Gear Tooth Forms}

General equations are given which define the involute tooth form based on pitch, $P$; pitch pressure angle $\phi_{p}$; pitch radius, $R_{p}$; circular pitch tooth thickness $t_{p}$; root radius, $R_{r}$; fillet radius, $r$; and tooth width, $W$. The load position on the tooth can be defined in terms of the distance along the line of action from the pitch circle, $S$, or by the contact or load radius $R_{L}$ (fig. 2). Knowing these eight quantities, the basic tooth parameters common to all three tooth forms (fig. 1), are

number of teeth: $N=2 P R_{p}$

base radius: $R_{B}=R_{p} \operatorname{Cos} \phi_{p}$

base radius included tooth angle: $\alpha_{B}=t_{p} / 2 R_{p}+$ Tan $\phi_{p}-\phi_{p}$

contact radius: $R_{L}^{2}=S^{2}+2 R_{p} \operatorname{Sin} \phi_{p} S+R_{p}^{2}$

contact pressure angle: $\operatorname{Cos} \phi_{L}=R_{B} / R_{L}$

contact included tooth angle: $\alpha_{L}=\alpha_{B}-\operatorname{Tan} \phi_{L}+\phi_{L}$

contact tooth thickness: $h_{L}=2 R_{L} \operatorname{Sin} \alpha_{L}$

contact load angularity with $L: \phi_{L}^{\prime}=\left(\phi_{L}-\alpha_{L}\right)$

Gear Tooth Form S; standard case: $R_{r}^{2}+2 r R_{r} \geq R_{B}^{2}$ (fig. 2)

$\overline{R^{2}}=\left(R_{r}+r\right)^{2}-2 r \sqrt{ }\left(R_{r}+r\right)^{2}-R_{B}^{2}+r^{2}$

$\operatorname{Cos} \bar{\phi}=R_{B} / \bar{R}$

$\bar{\alpha}=\alpha_{B}-\operatorname{Tan} \bar{\phi}+\phi$

$\bar{h}=2 \bar{R} \operatorname{Sin} \bar{\alpha}$

$\bar{\gamma}=\phi^{\prime}=(\bar{\phi}-\bar{\alpha})$

$l_{o}=\left[R_{L} \operatorname{Cos} \alpha_{L}-\left(h_{L} \operatorname{Tan} \phi_{L}^{\prime}\right) / 2-(\bar{R} \operatorname{Cos} \bar{\alpha}+r \operatorname{Sin} \bar{\gamma})\right]$ (stress)

$h_{o}=2 \bar{R} \operatorname{Sin} \bar{\alpha}-2 r(1-\operatorname{Cos} \bar{\gamma})=\bar{h}-2 r(1-\operatorname{Cos} \bar{\gamma})$

The term $\gamma_{s}$ is iterated using equation (19).

$h_{s}=h_{o}+2 r\left(1-\operatorname{Cos} \gamma_{s}\right)$

$l_{s}^{\prime}=l_{o}+r \operatorname{Sin} \gamma_{s}$

$l_{s}=l_{s}^{\prime}+\left(h \operatorname{Tan} \phi_{L}^{\prime}\right) / 2$

The term $\gamma_{F}$ is iterated using equation (7) as in.

$X=R \operatorname{Cos} \alpha-\bar{R} \operatorname{Cos} \bar{\alpha}$

$\bar{l}=R_{L} \operatorname{Cos} \alpha_{L}-\left(h_{L} \operatorname{Tan} \phi_{L}^{\prime}\right) / 2-R \operatorname{Cos} \bar{\alpha} \quad$ (compliance) 
The term $R_{L}^{\prime}$ is iterated until $\left(R_{\mathcal{L}} \operatorname{Cos} \alpha_{L}^{\prime}-\bar{R} \operatorname{Cos} \bar{\alpha}\right)=\bar{l}$.

$h_{L}^{\prime}=2 R_{L}^{\prime} \operatorname{Sin} \alpha_{L}^{\prime}$

Gear Tooth Form A; tangent Case: $R_{r}^{2}+2 r R_{r}<R_{B}^{2}$ (fig. 18(a))

$\bar{\gamma}=\alpha_{B}$

$\left.\operatorname{Sin} \alpha_{r}=r / R_{r}+r\right)$

$h_{o}=2\left(R_{r}+r\right) \operatorname{Sin}\left(\alpha_{B}+\alpha_{r}\right)-2 r$

$l_{o}=R_{L} \operatorname{Cos} \alpha_{L}-\left(h_{L} \operatorname{Tan} \phi_{L}^{\prime}\right) / 2-\left(R_{r}+r\right) \operatorname{Cos}\left(\alpha_{B}+\alpha_{r}\right)$

$h_{B}=2 R_{B} \operatorname{Sin}(-\bar{\gamma})=2 R_{B} \operatorname{Sin} \alpha_{B}$

Between the tangency point of the fillet and base circle, for example, $\bar{R} \leq R \leq R_{B}$,

$$
\begin{aligned}
h & =\frac{h_{B}}{R_{B}}\left[\left(R_{r}+r\right) / \operatorname{Cos} \alpha_{r}+X / \operatorname{Cos} \bar{\gamma}\right] \\
& =h_{B} \frac{R}{R_{B}}, \text { where } X=(R-\bar{R}) \operatorname{Cos} \alpha_{B}
\end{aligned}
$$

$\alpha_{s}$ is iterated using equation (19), and $h_{s}, l_{s}^{\prime}$, and, $l_{s}$ are the same as for form $\mathrm{S}$

$\alpha_{F}$ is iterated using equation (7), but including additional beam section $\left(R_{B}-\bar{R}\right) \operatorname{Cos} \alpha_{B}$

Gear Tooth form B, parallel case: $R_{r}^{2}+2 r R_{r}<R_{B}^{2}$ (fig. 18(b))

$\bar{\gamma}=-\bar{\theta}$

$\bar{\theta}=\pi / N$ or $180^{\circ} / N$

$\delta=R_{B} \operatorname{Sin}\left(\bar{\theta}-\alpha_{B}\right)-R$

$\Delta=R_{B} \operatorname{Cos}\left(\bar{\theta}-\alpha_{B}\right)-\left(R_{r}+r\right)$

$l_{o}=R_{L} \operatorname{Cos} \alpha_{L}-R_{B} \operatorname{Cos} \alpha_{B}+\Delta \operatorname{Cos} \bar{\theta}+r \operatorname{Sin} \bar{\theta}-\left(h_{L} \operatorname{Tan} \phi_{L}^{\prime}\right) / 2$

$h_{o}=h_{B}-2 \Delta \operatorname{Sin} \bar{\theta}-2 r(1-\operatorname{Cos} \bar{\theta})$

$h_{B}=2 R_{B} \operatorname{Sin} \alpha_{B}$

Between the tangency point of fillet and base circle, for example, $0<X<\Delta \operatorname{Cos} \bar{\theta}$,

$\gamma_{s}$ is iterated using equation (19), and $h_{s}, l_{s}^{\prime}$, and $l_{s}$ are the same as for form S.

$\gamma_{F}$ is iterated using equation (17) but including beam section $\Delta \operatorname{Cos} \bar{\theta}$ 

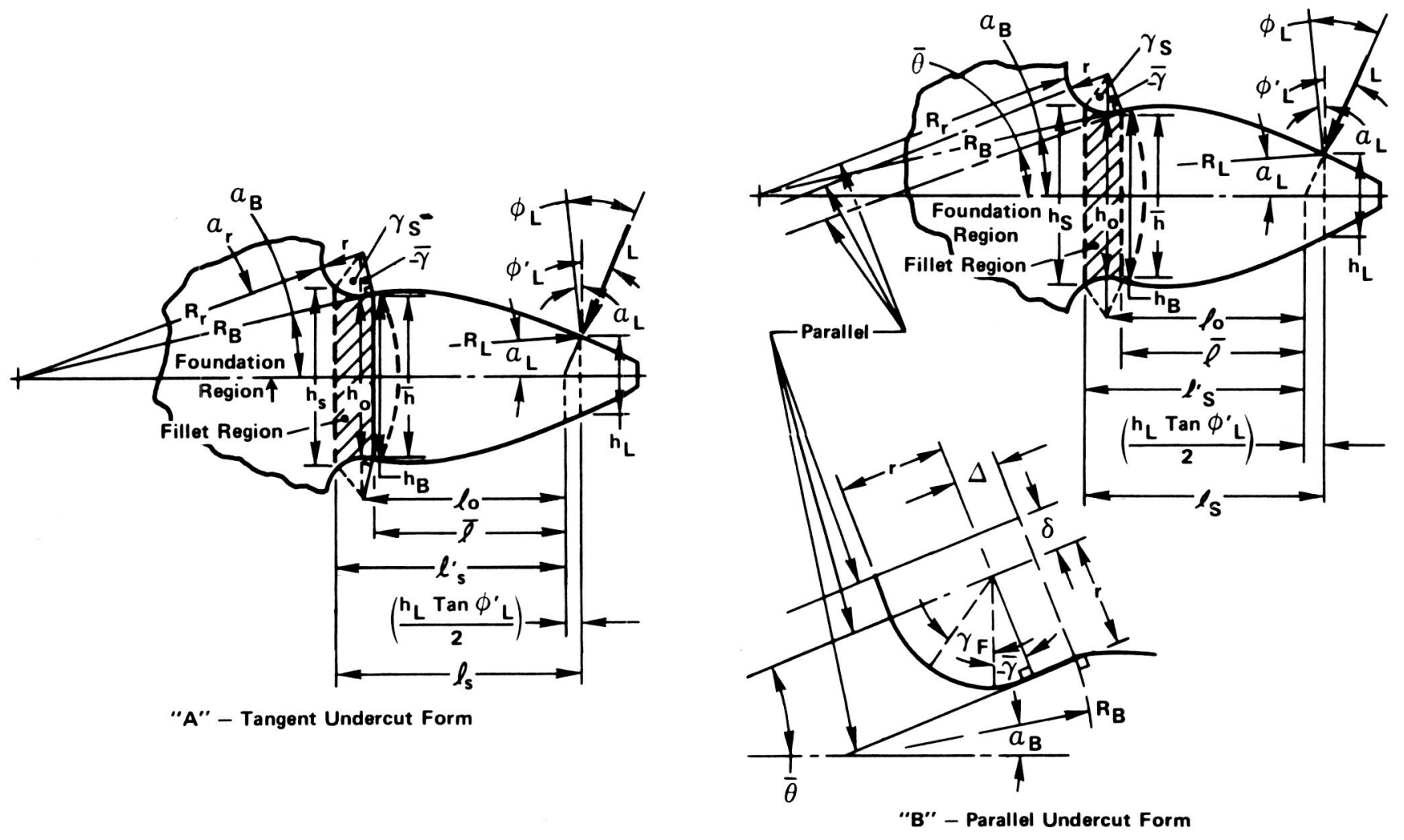

Figure 18. - Fillet regions for tooth forms $A$ and $B$. 